\title{
CHIARITÉ
}

UNIVERSITÄTSMEDIZIN BERLIN

\section{Altered inhibition and excitation in neocortical circuits in congenital microcephaly}

Sami Zaqout, Kathrin Blaesius, Yuan-Ju Wu, Stefanie Ott, Nadine Kraemer, Lena-Luise Becker, Marta Rosário, Christian Rosenmund, Ulf Strauss, Angela M. Kaindl

\section{Document type}

Postprint (accepted version)

This version is available at

https://doi.org/10.17169/refubium-32816

\section{Citation details}

Zaqout S, Blaesius K, Wu Y-J, Ott S, Kraemer N, Becker L-L, et al. Altered inhibition and excitation in neocortical circuits in congenital microcephaly. Neurobiology of Disease. Elsevier BV; 2019. p. 130-143. DOI: 10.1016/j.nbd.2019.05.008

\section{Terms of use}

This work is licensed under a Creative Commons Attribution-NonCommercial-NoDerivatives 4.0 International license: https://creativecommons.org/licenses/by-nc-nd/4.0/ 


\section{Altered inhibition and excitation in neocortical circuits in congenital microcephaly}

Sami Zaqout, ${ }^{1-4 \S}$ Kathrin Blaesius,,${ }^{1-4 \S}$ Yuan-Ju Wu, ${ }^{5}$ Stefanie Ott, ${ }^{1}$ Nadine Kraemer,,${ }^{1-3}$ LenaLuise Becker, ${ }^{1-3}$ Marta Rosário, ${ }^{1}$ Christian Rosenmund, ${ }^{4,5,6}$ Ulf Strauss, ${ }^{1 \S}$ Angela M. Kaindl, ${ }^{1-4 \$ \# ~}$ ${ }^{1}$ Charité - Universitätsmedizin Berlin, Institute of Cell- and Neurobiology, Charitéplatz 1, 10117 Berlin, Germany

${ }^{2}$ Charité - Universitätsmedizin Berlin, Center for Chronically Sick Children (Sozialpädiatrisches Zentrum, SPZ), Augustenburger Platz 1, 13353 Berlin, Germany

${ }^{3}$ Charité - Universitätsmedizin Berlin, Department of Pediatric Neurology, Augustenburger Platz 1, 13353 Berlin, Germany

${ }^{4}$ Berlin Institute of Health (BIH), Anna-Louisa-Karsch Strasse 2, 10178 Berlin, Germany ${ }^{5}$ Charité - Universitätsmedizin Berlin, NeuroCure, Charitéplatz 1, 10117 Berlin, Germany

${ }^{6}$ Charité - Universitätsmedizin Berlin, Institute of Neurophysiology, Charitéplatz 1, 10117 Berlin, Germany

§These authors contributed equally to this work.

\#Corresponding author: Dr. Angela M. Kaindl, Institute for Cell Biology and Neurobiology, Charité - Universitätsmedizin Berlin, Charitéplatz 1, 10117 Berlin. Tel/Fax: +49 (0)30 450 566112/920. Email: angela.kaindl@charite.de.

\section{Running title}

Cdk5rap2 and neocortical E/l balance 


\section{Abstract}

2 Congenital microcephaly is highly associated with intellectual disability. Features of autosomal 3 recessive primary microcephaly subtype $3(\mathrm{MCPH} 3)$ also include hyperactivity and seizures.

4 The disease is caused by biallelic mutations in the Cyclin-dependent kinase 5 regulatory 5 subunit-associated protein 2 gene CDK5RAP2. In the mouse, Cdk5rap2 mutations similar to 6 the human condition result in reduced brain size and a strikingly thin neocortex already at early 7 stages of neurogenesis that persists through adulthood. The microcephaly phenotype in MCPH 8 arises from a neural stem cell proliferation defect. Here, we report a novel role for Cdk5rap2 in 9 the regulation of dendritic development and synaptogenesis of neocortical layer $2 / 3$ pyramidal neurons. Cdk5rap2-deficient murine neurons show poorly branched dendritic arbors and an increased density of immature thin spines and glutamatergic synapses in vivo. Moreover, the excitatory drive is enhanced in ex vivo brain slice preparations of Cdk5rap2 mutant mice. Concurrently, we show that pyramidal neurons receive fewer inhibitory inputs. Together, these findings point towards a shift in the excitation - inhibition balance towards excitation in Cdk5rap2 mutant mice. Thus, MCPH3 is associated not only with a neural progenitor proliferation defect but also with altered function of postmitotic neurons and hence with altered connectivity.

\section{Key words}

20 Cdk5rap2; microcephaly; neuronal differentiation; synaptic transmission; dendritic 21 morphogenesis 


\section{Introduction}

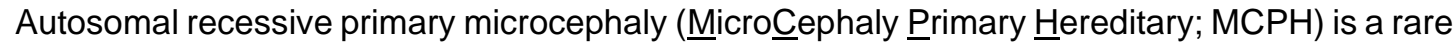
neurodevelopmental disorder characterized by intellectual disability and microcephaly at birth due to severe reduction in brain volume that affects especially the neocortex (Kaindl et al., 2010; Kraemer et al., 2011). So far, twenty genes have been linked to MCPH and are referred to as MCPH1-20 (DiStasio et al., 2017; Kadir et al., 2016; Moawia et al., 2017; reviewed in Zaqout et al., 2017b). Some MCPH patients have epilepsy and/or a hyperactivity disorder (Passemard et al., 2009). Biallelic mutations in the gene encoding centrosomal Cyclindependent kinase 5 regulatory subunit-associated protein 2 (CDK5RAP2) lead to MCPH3 (MIM*604804) (Bond et al., 2005; Hassan et al., 2007; Issa et al., 2013b).

$\mathrm{MCPH}$ is seen as model disorder for microcephaly. Thus, unraveling pathomechanisms of this disease can convey insight into basic mechanisms of physiologic brain development, particularly of brain growth and cortex formation. One current model for the microcephaly phenotype in $\mathrm{MCPH}$ invokes a premature shift from symmetric to asymmetric cell divisions and thus premature neurogenesis with a subsequent depletion of the progenitor pool (Buchman et al., 2010; Fish et al., 2006; Lizarraga et al., 2010). In addition, increased apoptosis of neural progenitors and postmitotic cells has been reported in MCPH3 mice (Kraemer et al., 2015; Lizarraga et al., 2010). Premature neurogenesis due to CDK5RAP2 dysfunction may be secondary to disturbances in cleavage plane orientation of apical neural progenitors (Lizarraga et al., 2010), altered centriole engagement and cohesion (Barrera et al., 2010), microtubule organizing dysfunction of the centrosome through interaction with the gamma tubulin ring complex (Fong et al., 2008), improper spindle formation and chromosome segregation (Bond et al., 2005). Most studies regarding the pathophysiology of MCPH have focused on division and survival of neural progenitors. The effect of MCPH proteins on neuronal differentiation and function within the neural circuit, however, has been largely neglected. Since a smaller brain does not necessarily imply intellectual disability but $\mathrm{MCPH}$ patients often display such condition together with hyperactivity, and in some cases epilepsy, we reasoned that MCPH proteins may have additional roles in postmitotic neurons, during synaptogenesis and synaptic transmission. Also, neurodevelopmental disorders associated with intellectual disability and neuropsychiatric conditions are often associated with defects in dendritic arborization and spine formation. We 
have therefore addressed whether loss of Cdk5rap2 as seen in $\mathrm{MCPH} 3$ affects the function of differentiated neurons in the neocortex by performing morphological and electrophysiological studies on the established MCPH3 mouse model, Cdk5rap2 mutant or Hertwig's anemia mice (an/an). Our results demonstrate that Cdk5rap2 is essential for the maturation of the dendritic arbor and its synaptic connectivity and affects dendritic structure and synaptic connectivity in the mature brain.

\section{Results}

\subsection{Preserved neocortical layer organization but thin upper layers}

To address the role of Cdk5rap2 in mature neurons, we used the established Cdk5rap2 mouse model (Hertwig's anemia mice (an/an)) (Lizarraga et al., 2010). Cdk5rap2 mutant mice (an/an) display reduced overall brain size. Neocortical area was reduced to $46 \%$ and parietal cortical thickness to $67 \%$ (Fig 1) at birth, in line with the findings reported by (Lizarraga et al., 2010). These structural changes persisted into adulthood (reduction in neocortical area to $50 \%$ and parietal cortical thickness to $68 \%$; Fig 1) and were associated with a strong reduction in the total number of cells in the neocortex of P0 and adult an/an mice (Fig 2A and B).

Cortical layer organization was grossly undisturbed, as revealed by immunostaining with the layer 2-4 marker Cux1 and the layer 5-6 marker Ctip2 (Fig 2A). While both Cux1+ upper layers and $\mathrm{Ctip2}^{+}$deep layers were thinner (Fig $2 \mathrm{C}$ ), only the relative thickness of upper layers with respect to the total cortical thickness was reduced in P0 and adult an/an mice (Fig 2C and S1 Table). The relative thickness of deep layers with respect to total cortical thickness remained unchanged (Fig 2C). Cell counts per view-field were reduced for Cux1+ and Ctip2 ${ }^{+}$neocortical neurons (Fig 2D and Table S1). However, the relative number of both Cux $1^{+}$and Ctip2+ neocortical neurons (Fig 2D) with respect to total DAPI+ nuclei was not changed, suggesting that neuronal cell fate is unaltered. Together, these findings indicate that despite the large reduction in cell numbers and cortical area, cortical architecture remains relatively undisturbed.

\subsection{Reduced dendritic complexity of layer $2 / 3$ pyramidal neurons}

We next analyzed the dendritic tree of layer $2 / 3$ neocortical neurons of adult an/an and littermate +/+ mice in Golgi stained brain sections. We quantified the dendritic complexity of 
individual neurons using Sholl analysis (SHOLL, 1953). Mutant Cdk5rap2 in an/an mice is associated with a downwards shift of the Sholl curve for both apical and basal dendrites of layer $2 / 3$ pyramidal neurons, indicating a marked reduction in the complexity of these dendrites (Fig $3 \mathrm{~A}, \mathrm{~B}$ and Fig. S2). In line, although the number of primary dendrites were similar $(+/+=5.3 \pm$ 0.2 vs. $a n / a n=4.9 \pm 0.2$ dendrites, $p=0.2, \mathrm{TT}$ ), numbers of secondary and tertiary dendrites were reduced in an/an (secondary: $+/+=10.4 \pm 0.3$ vs. an $/ a n=8.8 \pm 0.3$ dendrites, $p<0.002$, TT; tertiary: $+/+=18.4 \pm 1.3$ vs. an/an $=10.5 \pm 0.8$ dendrites, $p<0.0001, T T ; n=44+/+$ and 39 an/an neurons from $6+/+$ and 4 an/an animals; Fig 3B).

As neuronal surface area and input resistance are inversely proportional, the reduction in dendritic complexity could alter the intrinsic properties of an/an layer 2/3 neocortical neurons. We therefore performed whole cell patch clamp recordings on these neurons. Indeed, when compared to control neurons, an/an neurons showed an increased input resistance $(\mathrm{Rin}+/+=$ $81.5 \pm 8.6 \mathrm{M} \Omega, \mathrm{n}=15$ vs. Rinan/an $=153.5 \pm 15.1 \mathrm{M} \Omega, \mathrm{n}=17, \mathrm{p}<0.001, \mathrm{MWU}$, Fig 3C) while resting membrane potential remained similar $\left(\mathrm{V}_{\mathrm{M}+/+}=-79.1 \pm 2.4 \mathrm{mV}, \mathrm{n}=14 \mathrm{vs}\right.$. $\mathrm{V}_{\mathrm{Man} / a n}=-74.9$ $\pm 2.5 \mathrm{mV}, \mathrm{n}=10, \mathrm{p}=0.1, \mathrm{MWU})$. Accordingly, neuronal membrane capacitance was smaller in an/an $\left(\mathrm{C}_{+/+}=125.7 \pm 11.3 \mathrm{pF}\right.$ vs. $\left.\mathrm{C}_{a n / a n}=94.9 \pm 6.8 \mathrm{pF}, \mathrm{p}<0.03, \mathrm{MWU}\right)$. As a consequence, the rheobase, i.e. the minimal current amplitude for action potential induction, decreased (Irheo+/+ $=295.4 \pm 23.6 \mathrm{pA}, \mathrm{n}=13 \mathrm{vs}$. Irheoan/an $186.9 \pm 44.3 \mathrm{pA}, \mathrm{n}=13, \mathrm{p}=0.04 \mathrm{TT}$, Fig $3 \mathrm{E}$ and F) and neuronal gain, given by the slope of the $\mathrm{F} / \mathrm{I}$ relationship, increased $(\mathrm{F} / \mathrm{Islope+/+}=115.5 \pm 14.9$ $\mathrm{AP} / \mathrm{nA}, \mathrm{n}=14 \mathrm{vs} . \mathrm{F} / \mathrm{Islope}_{\mathrm{s} / \mathrm{an}}=159.6 \pm 18.9 \mathrm{AP} / \mathrm{nA}, \mathrm{n}=13, \mathrm{p}=0.08, \mathrm{TT}$, Fig $3 \mathrm{E}$ and $\left.\mathrm{G}\right)$. Thus, our data imply that the reduced dendritic arborization of an/an neurons is associated with intrinsic pro-excitatory neuronal properties. While reduced dendritic arborization may impact on incoming dendritic signals by reducing the catchment area but increasing the electrotonic compactness (Spruston et al., 1993), the latter properties putatively privilege small and remote inputs.

\subsection{Increased spine density, excitatory synapse number, and spontaneous glutamatergic transmission}

Our morphological findings and the fact that MCPH patients can suffer from hyperactive behavior and seizures prompted us to study the dendritic spine and synapse properties of layer 
2/3 neurons in adult an/an mice. We first analyzed dendritic spines in Golgi-stained pyramidal neurons and found an increase in the density of spines along apical and basal dendrites $(+/+$ $=0.58 \pm 0.04 \mu \mathrm{m}^{-1}$ vs. an/an $=0.76 \pm 0.03 \mu \mathrm{m}^{-1}, \mathrm{p}=0.0007$, TT, Fig $3 \mathrm{H}$ and I). We next assessed whether spine morphology was altered in the mutants. We detected a significant increase in the number of thin-shaped "immature" spines in an/an mice compared to $+/+$ littermates $(+/+=16.2 \pm 2.5 \%$ vs. an/an $=28.5 \pm 3.2 \%, p<0.005$, TT, Fig $3 \mathrm{H}$ and I). Thin spines, containing long necks and small spine heads, are thought to represent immature spines (Dailey and Smith, 1996). To address whether the increase in spine density and altered spine morphology results in a change in excitatory transmission, we recorded spontaneous excitatory postsynaptic currents (sEPSCs) of layer 2/3 pyramidal neurons in ex-vivo adult brain slices (Fig 3J). sEPSCs mainly correspond to spontaneous presynaptic glutamate vesicle release (Schuster et al., 2015), since spontaneous action potentials in layer 2/3 neurons in slices are unlikely events. In accordance with the elevated spine density we found an increase in the total excitatory charge transfer $\left(\mathrm{Q}_{\mathrm{T}_{+/+}}=1010.4 \pm 135.3 \mathrm{fC}, \mathrm{n}=15 \mathrm{vs}\right.$. $\mathrm{Q}_{\mathrm{Tan} / \mathrm{an}}=1969.2 \pm 460.2 \mathrm{fC}, \mathrm{n}$ $=14, p<0.05, \mathrm{MWU}$, Fig $3 \mathrm{~K})$ mainly due to an augmented sEPSCs frequency $\left(\mathrm{f}_{+/+}=18.1 \pm 0.8\right.$ events/s, $n=15$ vs. $f_{a n / a n}=29.4 \pm 1.6$ events $/ s, n=14, p<0.0001$, TT, Fig 3L), since sEPSC kinetics were similar (decay: $\tau_{+/+}=7.8 \pm 0.6 \mathrm{~ms}, \mathrm{n}=15 \mathrm{vs} . \tau_{a n / a n}=8.1 \pm 0.8 \mathrm{~ms}, \mathrm{n}=14, \mathrm{p}=0.6$, $M W U)$. The increase in frequency might be in part due to the reduced neuronal size in an/an mice, making them electrically more compact and less leaky (Spruston et al., 1993).

Most of the additional spines in the mutant displayed "immature" thin spine morphology. Since spine head width has been correlated to the level of AMPA receptors, this could suggest a reduced number of AMPARs per spine (Matsuzaki et al., 2001). In our study mean EPSC amplitude and amplitude density, as indirect measures of AMPA receptor number in the postsynaptic density (Nair et al., 2013) did not differ between groups $\left(I_{+/+}=10.5 \pm 0.6 \mathrm{pA}, \mathrm{n}=\right.$ 15 vs. $I_{a n / a n}=8.8 \pm 0.7 \mathrm{pA}, \mathrm{n}=14, \mathrm{p}=0.09, \mathrm{TT}$, Fig $3 \mathrm{M}$, inset; $/ / C_{+/+}=0.092 \pm 0.009 \mathrm{pA} / \mathrm{pF}, \mathrm{n}$ $\left.=15 \mathrm{vs} . \mathrm{I} / \mathrm{C}_{\text {an } / a n}=0.097 \pm 0.008 \mathrm{pA}, \mathrm{n}=14, \mathrm{p}=0.65, \mathrm{MWU}\right)$, excluding an overall postsynaptic phenotype in an/an neurons.

Survival to adulthood is a very rare event for an/an mice. To test whether the changes in cell morphology was directly caused by the loss of gene function or rather the result of secondary compensatory effects, we investigated layer $2 / 3$ neuronal activity in an/an mice at 
an early stage of synaptogenesis using ex-vivo P6/7 brain slices. At this stage of development, we did not observe significant changes in membrane resistance, neuronal excitability $\left(\mathrm{R}_{\mathrm{in}+/+}=\right.$ $598.6 \pm 50.7 \mathrm{M} \Omega, \mathrm{n}=29 \mathrm{vs}$. Rinan/an $=657.9 \pm 53.6 \mathrm{M} \Omega, \mathrm{n}=35, \mathrm{p}=0.45 ;$ Irheo+/+ $=29.2 \pm 3.7 \mathrm{pA}$ vs. Irheoan/an $=35.8 \pm 5.6 \mathrm{pA}, \mathrm{p}=1, \mathrm{MWU} ; \mathrm{Fl}_{\text {slope }+/+}=334.5 \pm 21.5 \mathrm{AP} / \mathrm{nA}, \mathrm{n}=29$ vs. Fl $\mathrm{Fl}_{\text {slopean/an }}$ $=421.1 \pm 44.8 \mathrm{AP} / \mathrm{nA}, \mathrm{n}=35, \mathrm{p}=0.2, \mathrm{MWU} ; \mathrm{V}_{\mathrm{M}++}=72.6 \pm 1.1 \mathrm{mV} \mathrm{n}=22 \mathrm{vs} . \mathrm{V}_{\mathrm{Man} / a n}=68.9 \pm$ $1.7 \mathrm{mV}, \mathrm{n}=27, \mathrm{p}=0.2$ Fig $4 \mathrm{~A}-\mathrm{D})$ or neuronal membrane capacitance $\left(\mathrm{C}_{+/+}=75.1 \pm 5.4 \mathrm{pF}\right.$ vs. $\left.\mathrm{C}_{a n / a n}=74.5 \pm 4.1 \mathrm{pF}, \mathrm{p}=0.99, \mathrm{MWU}\right)$. This indicates comparable electrotonic compactness at this stage, enabling us to investigate electrophysiological differences independent of gross morphological changes. Excitatory synaptic drive was already elevated in the mutant as evident by the $48 \%$ increase in total excitatory charge transfer $\left(Q_{T_{+/+}}=93.3 \pm 16.6 \mathrm{fC}, \mathrm{n}=23 \mathrm{vs}\right.$. $\mathrm{Q}_{\mathrm{Tan} / \mathrm{an}}$ $=138.6 \pm 18.3 \mathrm{fC}, \mathrm{n}=28, \mathrm{p}<0.08$, MWU; Fig $4 \mathrm{~F})$ and $53 \%$ increase in sEPSC frequency $\left(\mathrm{f}_{+++}\right.$ $=2.18 \pm 0.22$ events $/ \mathrm{s}, \mathrm{n}=29$ vs. $\mathrm{f}_{a n / a n}=3.33 \pm 0.27$ events/s, $\mathrm{n}=38, \mathrm{p}=0.008$, MWU; Fig 4E and $G)$. This increase in frequency was not accompanied by a change in amplitude $\left(I_{+/+}=6.24\right.$ $\pm 0.39 \mathrm{pA}, \mathrm{n}=29 \mathrm{vs}$. $I_{a n / a n}=5.84 \pm 0.31 \mathrm{pA}, \mathrm{n}=38, \mathrm{p}=0.3$, MWU; Fig $4 \mathrm{H}$ ), amplitude density $\left(/ / C_{+/+}=0.087 \pm 0.005 \mathrm{pA} / \mathrm{pF}, \mathrm{n}=29 \mathrm{vs} . / / C_{a n / a n}=0.084 \pm 0.005 \mathrm{pA}, \mathrm{n}=38, \mathrm{p}=0.89, \mathrm{MWU}\right)$ or kinetics (decay: $\tau_{+/+}=7.8 \pm 0.5 \mathrm{~ms}, \mathrm{n}=29 \mathrm{vs} . \tau_{a n / a n}=8.1 \pm 0.6 \mathrm{~ms}, \mathrm{n}=38, \mathrm{p}=0.7, \mathrm{TT}$ ).

Changes in sEPSC frequency in P6-7 an/an mice are unlikely due to the detection of more events from distal dendrites because electrical compactness was similar in both genotypes. The increase could be mediated by changes in spontaneous presynaptic firing (but see TTX-experiments under 2.5) or may be linked to presynaptic vesicle release probability (del CASTILLO and KATZ, 1954). We therefore evoked paired pulse responses in layer 2/3 neocortical neurons but found no alteration in the paired pulse ratio of an/an cells (Fig $4 \mathrm{I}$ and J), suggesting that presynaptic release probability is unaffected. Finally, immunohistochemical staining for pre- (VGlut1) and postsynaptic (PSD95) markers revealed a $66 \%$ increase in VGlut1/PSD95-positive synapses already at P6/7 in an/an layer 2/3 neurons (Fig 4K and L). Taken together, these results point towards an increase in excitatory drive of layer $2 / 3$ pyramidal neurons in an/an mice regardless of their age or severity of alteration (as indicated by early death $v s$. survival). 


\subsection{Minor influence of Cdk5rap2 on dendritic complexity or excitatory transmission in}

cultured neocortical pyramidal neurons

Altered Cdk5rap2 function may contribute, in a cell intrinsic fashion, to reduced dendritic complexity and elevated excitatory drive of an/an mice layer 2/3 neurons. Cdk5rap2 has been shown to interact with chromatin associated Cdc20-anaphase promoting complex (Cdc20APC) protein (Kraemer et al., 2011; X. Zhang et al., 2009) that can influence dendritic development (Kim et al., 2009). Therefore, we investigated the effect of Cdk5rap2 loss of function in vitro. We first used autaptic (i.e. singly cultured neurons) primary neuronal cultures from newborn +/+ and an/an cortices that allow for detailed quantification of synaptic properties. Neurons derived from an/an cultures had a reduced soma size $\left(A_{+/+}=148.6 \pm 7.7 \mu m^{2}, n=28\right.$ vs. $A_{a n / a n}=126.3 \pm 5.6 \mu \mathrm{m}^{2}, \mathrm{n}=38, \mathrm{p}=0.02$, TT). We found no significant change in the total length of dendrites $\left(\mathrm{Ld}+/+_{+}=962.9 \pm 92.8 \mu \mathrm{m}, \mathrm{n}=28 \mathrm{vs}\right.$. $\mathrm{Ld}_{a n / a n}=878.8 \pm 74.9 \mu \mathrm{m}, \mathrm{n}=36, \mathrm{p}=$ $0.7, \mathrm{MWU})$. The axonal length was reduced by nearly $30 \%$ when compared to those from $+/+$ cultures $\left(\mathrm{L}_{\mathrm{aan} / \mathrm{an}}=986.9 \pm 159.8 \mu \mathrm{m}, \mathrm{n}=23 \mathrm{vs} . \mathrm{L}_{\mathrm{a}++}=1314.1 \pm 172.1 \mu \mathrm{m}, \mathrm{n}=17, \mathrm{p}=0.07\right.$, MWU, Fig 5A and C). However, numbers of primary dendrites (+/+: $5.4 \pm 0.6, n=20$; an/an: $5.7 \pm 0.4, \mathrm{n}=31, \mathrm{p}=0.46, \mathrm{MWU})$ and dendritic tips $(+/+: 20.9 \pm 2.1, \mathrm{n}=20$ an/an: $22.0 \pm 1.6$, $\mathrm{n}=31, \mathrm{p}=0.7, \mathrm{TT})$ did not differ between the groups, resulting in a comparable branching index $(+/+: 4.2 \pm 0.4, \mathrm{n}=20$, an/an: $5.7 \pm 0.25, \mathrm{n}=31, \mathrm{p}=0.57$, TT, Fig $5 \mathrm{~A}$ and $\mathrm{B})$.

We next analyzed the synaptic transmission of glutamatergic autaptic neurons but found no significant difference in evoked responses (EPSCs; $I_{+/+}=5.54 \pm 0.67 \mathrm{nA}, \mathrm{n}=65$ vs. $I_{a n / a n}=5.15 \pm 0.67 \mathrm{nA}, \mathrm{n}=54, \mathrm{p}=0.64$, MWU, Fig 5D) nor in mEPSC rates or amplitudes between $+/+$ and an/an mouse neurons $\left(\mathrm{f}_{+/+}=2.3 \pm 0.4\right.$ events/s, $\mathrm{n}=52$ vs. $\mathrm{f}_{\mathrm{an} / \mathrm{an}}=2.7 \pm 0.4$ events/s, $\mathrm{n}=45, \mathrm{p}=0.3, \mathrm{MWU} ; I_{t_{+}}=24.5 \pm 1.7 \mathrm{pA}, \mathrm{n}=52 \mathrm{vs} . \mathrm{I}_{a n / a n}=23.6 \pm 1.3 \mathrm{pA}, \mathrm{n}=45, \mathrm{p}$ $=0.9, \mathrm{MWU}$; Fig $5 \mathrm{H}$ to J). Utilizing responses induced by hypertonic solution, we next determined the size of the readily releasable pool (RRP $=$ the amount of primed synaptic vesicles; (Rosenmund and Stevens, 1996)) in an/an compared to +/+ neurons and found, consistent with the unchanged evoked response, no alteration between wildtype and mutant neurons $\left(\mathrm{RRP}_{+/+}=307.2 \pm 51.4 \mathrm{pC}, \mathrm{n}=51\right.$ vs. $\mathrm{RRP}_{a n / a n}=416.5 \pm 71.5 \mathrm{pC}, \mathrm{n}=44, \mathrm{p}=0.3$, MWU; Fig 5E and F). The vesicular release probability (Pvr), as calculated by comparing evoked response and RRP size, was also comparable between +/+ and an/an neurons ( $\mathrm{Pvr}_{+/+}$ 
$=11.7 \pm 0.9 \%, \mathrm{n}=51 \mathrm{vs} . \mathrm{Pvr}_{a n / a n}=10.6 \pm 0.9 \%, \mathrm{n}=44, \mathrm{p}=0.9, \mathrm{TT}$, Fig 5G).

We further examined synapse formation on cortical neurons in dissociated cultures and found no differences. In detail, the density of glutamatergic presynaptic punctae was comparable (Fig 5K; VGlut1; +/+ = $3140 \pm 249$ puncta/0.15 mm², $\mathrm{n}=38$ vs. an/an $=3487 \pm$ 300 puncta/ $0.15 \mathrm{~mm}^{2}, \mathrm{n}=37, \mathrm{p}=0.4, \mathrm{MWU}$; from 3 independent cultures). Taken together, our results from the cultured neurons imply that changes induced by Cdk5rap2 mutation are not entirely cell intrinsic and require in-vivo like neuron-neuron interactions. Note that these results do not exclude an astrocytic malfunction in an/an, because both, autaptic and continental neuronal cultures were grown on non-mutated feeder astrocytes.

\subsection{Decreased inhibitory tone in ex-vivo slices of Cdk5rap2 mutants}

Given the observed increased excitatory drive at the soma of pyramidal Cdk5rap2 mutant neurons ex-vivo but not in singly cultured neurons and the known control of pyramidal neurons by inhibitory neurons, we again drew upon brain slice experiments to analyze the importance of neuronal interaction for the Cdk5rap2 phenotype. We first examined the inhibitory tone in ex-vivo brain slices by quantifying miniature inhibitory postsynaptic currents (mIPSC) (Fig 6A). At P6-7, we found that the Cdk5rap2 mutation is associated with decreased inhibitory charge transfer $\left(\mathrm{Q}_{\mathrm{T}_{+/+}}=126.3 \pm 13.5 \mathrm{fC}, \mathrm{n}=30\right.$ vs. $\mathrm{QT}_{\mathrm{Tn} / \mathrm{an}}=102.4 \pm 12.9 \mathrm{fC}, \mathrm{n}=32, \mathrm{p}<0.03, \mathrm{MWU}$, Fig 6B). A comparison of frequency and amplitude of mIPSC events showed that the decreased tone was most likely due to the decreased frequency of events $\left(f_{+/+}=1.40 \pm 0.05\right.$ events/s vs. $f_{a n / a n}=1.04 \pm 0.05$ events $\left./ \mathrm{s}, \mathrm{p}<0.0001, \mathrm{MWU}\right)$ because mIPSC amplitude $\left(I_{t_{+}}=11.36 \pm 0.95\right.$ $\mathrm{pA}, \mathrm{n}=30 \mathrm{vs}$. $I_{a n / a n}=12.28 \pm 0.94 \mathrm{pA}, \mathrm{n}=32, \mathrm{p}=0.2$, MWU, Fig $6 \mathrm{C}$ and $\mathrm{D}$ ), amplitude density $\left(I / C_{+/+}=0.129 \pm 0.009 \mathrm{pA} / \mathrm{pF} v s . / / C_{a n / a n}=0.131 \pm 0.009 \mathrm{pA}, \mathrm{p}=0.86, \mathrm{TT}\right), \mathrm{mIPSC}$ kinetics (decay: $\tau_{+/+}=8.34 \pm 0.21 \mathrm{~ms}, \mathrm{n}=30$ vs. $\tau_{a n / a n}=8.62 \pm 0.46 \mathrm{~ms}, \mathrm{n}=32, \mathrm{p}=0.8, \mathrm{MWU}$ ) and neuronal membrane capacitance $\left(\mathrm{C}_{+/+}=90.2 \pm 13.1 \mathrm{pF}\right.$ vs. $\mathrm{C}_{a n / a n}=89.0 \pm 8.3 \mathrm{pF}, \mathrm{p}=0.7$, MWU) were similar in both genotypes. This indicates that less inhibitory synapses are formed on pyramidal neurons already in emerging neural networks, which suggests that the density and/or axonal tree formation of inhibitory neurons is impaired.

The ability of synapse formation itself was not disturbed in cultured GABAergic autaptic neurons (Fig 6E) of an/an mice as synaptic transmission was comparable in the two groups. In 
particular, evoked responses were similar in both genotypes (IPSCs; $I_{+++}=4.81 \pm 1.41 \mathrm{nA}, \mathrm{n}=$ 8 vs. $I_{a n / a n}=4.13 \pm 2.57 \mathrm{nA}, \mathrm{n}=15, \mathrm{p}=0.62, \mathrm{TT}$, Fig $6 \mathrm{~F}$ and $\mathrm{G}$ ). Consistent with the unchanged evoked response, $\mathrm{RRP}$ size $\left(\mathrm{RRP}_{+/+}=2592.8 \pm 650.3 \mathrm{pC}, \mathrm{n}=8 \mathrm{vs} . \mathrm{RRP}_{a n / a n}=2179.7 \pm 274.1\right.$ $\mathrm{pC}, \mathrm{n}=14, \mathrm{p}=0.6,77$; Fig $6 \mathrm{H}$ and $\mathrm{I})$ and $\mathrm{Pvr}\left(\mathrm{Pvr}_{+/+}=12.1 \pm 3.0 \%, \mathrm{n}=8 \mathrm{vs}\right.$. $\mathrm{Pvr}_{a n / a n}=16.5 \pm$ $2.6 \%, n=44, p=0.9, \mathrm{TT}$, Fig $6 \mathrm{~J}$ ) were also comparable between $+/+$ and an/an mice. Finally, mIPSC rates or amplitudes of $+/+$ and an/an mouse neurons $\left(\mathrm{f}_{+/+}=0.7 \pm 0.2\right.$ events/s, $\mathrm{n}=4 \mathrm{vs}$. $f_{a n / a n}=0.9 \pm 0.4$ events/s, $n=9, p=0.5, \mathrm{MWU} ; I_{+/+}=32.7 \pm 9.2 \mathrm{pA}, \mathrm{n}=4 \mathrm{vs} . I_{a n / a n}=27.9 \pm 4.5$ $\mathrm{pA}, \mathrm{n}=9, \mathrm{p}=0.8$, MWU; Fig $6 \mathrm{~K}-\mathrm{M})$ and the number of inhibitory synapses (VGat; $+/+=2513.1$ \pm 197.2 puncta/ $/ 0.15 \mathrm{~mm}^{2}, \mathrm{n}=38$ vs. $a n / a n=3007.5 \pm 257.9$ puncta $/ 0.15 \mathrm{~mm}^{2}, \mathrm{n}=37, \mathrm{p}=0.2$, MWU, Fig 5J) were similar.

In search for a morphological correlate of decreased inhibition in Cdk5rap2 mutant mice, we stained the cortex for GABA, a marker for interneurons (Uematsu et al., 2008) that is also expressed in astrocytes (Yoon and Lee, 2014). However, astrocytes do not substantially contribute to the GABA+ cells at P6-7 (Fig S4). The total number of GABA+ cells in P6-7 an/an mice was smaller $\left(\mathrm{GABA}^{+}{ }_{++}=71.0 \pm 5.2\right.$ neurons per view-field, $\mathrm{n}=6$ animals vs. $\mathrm{GABA}^{+}{ }_{a n / a n}$ $=50.5 \pm 7.1$ neurons per view-field, $n=3$ animals, $p=0.048$, MWU; Fig 7A and $B$ ). This reduction matches the general diminution of the neocortex since the relative proportion of these neurons (compared to total $\mathrm{NeuN}^{+}$cells) was similar $\left(\mathrm{GABA}^{+} / \mathrm{NeuN}^{+}+{ }_{++}=4.9 \pm 0.5 \% \mathrm{n}=6\right.$ animals vs. GABA ${ }^{+} / \mathrm{NeuN}^{+}{ }_{a n} / a n=6.2 \pm 0.6 \% \mathrm{n}=3$ animals, $\mathrm{p}=0.1$, MWU; Fig $7 \mathrm{~A}$ and $\mathrm{B}$ ). In contrast, we found a decrease in both the total number of $\mathrm{GABA}^{+}$interneurons in adult an/an mice $\left(\mathrm{GABA}^{+}+{ }_{+}=37.3 \pm 5.2\right.$ neurons per view-field, $\mathrm{n}=6$ animals vs. $\mathrm{GABA}^{+}{ }_{a n / a n}=7.8 \pm 1.5$ neurons per view-field, $n=4$ animals, $p=0.0095$, MWU; Fig S3A and B) and in the relative proportion of these neurons $\left(\mathrm{GABA}^{+} / \mathrm{NeuN}^{+}{ }_{++}=2.7 \pm 0.4 \%, \mathrm{n}=6\right.$ animals $v s$. $\mathrm{GABA}^{+} / \mathrm{NeuN}^{+}{ }_{a n} / a n=1.2 \pm 0.2 \%, \mathrm{n}=4$ animals, $\mathrm{p}=0.0095, \mathrm{MWU}$; Fig S3A and B). In line with the reduced mIPSC frequencies, layer 2/3 from P6-7 an/an mice showed a trend towards decreased numbers of $\mathrm{VGat}^{+}$presynaptic inhibitory terminals in comparison to +/+ littermates $(+/+=110.3 \pm 18.0$ vs. an/an $=73.1 \pm 8.2, p=0.09$, TT; Fig $7 \mathrm{C}$ and $\mathrm{D})$. By co-staining the same slices with VGlut1 and calculating the ratio of VGlut1 and VGat positive punctae we found a markedly increased morphological excitation to inhibition (E/I) ratio of layer $2 / 3$ neurons in an/an mice $(+/+=1.3 \pm 0.2$ vs. an/an $=2.4 \pm 0.2, p=0.003$, TT; Fig 7D) as a result of a 
decrease in inhibitory relative to excitatory (see also Fig $4 \mathrm{~K}$ and $\mathrm{L}$ ) synapses. This is roughly in line with the functional E/I ratios calculated by dividing excitatory and inhibitory charge transfers $(+/+=1.14 \pm 0.3 \mathrm{vs}$. an/an $=1.6 \pm 0.2, p=0.056, \mathrm{MWU})$. The reduced inhibition (less mIPSCs and VGat positive terminals) is likely due to the decreased number of GABAergic synapses in the cortex, since neither inhibitory quantal amplitude nor IPSC decay kinetic was altered.

We reasoned that the reduced inhibitory influence observed in an/an neurons ex-vivo contributes to an elevated frequency of glutamatergic signals at the soma. If our hypothesis holds true, blocking GABAergic transmission should level out the differences in the number of excitatory events between the groups (i.e. particularly increase the frequency of glutamatergic signals in wild-types, similar to finding in Cdk5rap2 mutants). We therefore applied the GABAA receptor blocker bicuculline $(20 \mu \mathrm{M})$ to block inhibition and the sodium channel blocker tetrodotoxin $(1 \mu \mathrm{M})$ preventing increased pyramidal action potential firing induced by bicuculline (Turrigiano et al., 1998) and putative spontaneous interneuronal action potentials. Indeed, this treatment increased the frequency of excitatory events in $+/+(3.9 \pm 0.4$ to $5.5 \pm 0.4$ events/s, $\mathrm{n}=24, \mathrm{p}=0.02$, ANOVA-RM-B in $+/+$ ) but not in an/an littermates at P6/7 (5.4 \pm 0.4 to $5.8 \pm$ 0.4 events/s, $n=22, p=1$, ANOVA-RM-B in an/an neurons) (Fig 7E - G). Note that in a subset of experiments TTX alone did not change PSC frequencies in general ( $2.6 \pm 0.3 \mathrm{vs.} 2.8 \pm 0.3$ events/s, $n=17, p=1$, ANOVA-RM-B) or in on of the genotypes $(1.8 \pm 0.2$ vs. $1.9 \pm 0.3$ events/s, $n=9$ in $+/+$, and $3.6 \pm 0.4$ vs. $3.8 \pm 0.4$ events/s, $n=8$ in an/an, $p=1$, ANOVA-RM$\mathrm{B}$, respectively). This also renders a contribution of increased presynaptic firing to the elevated sEPSC frequencies in an/an mice (see 2.3) unlikely. We cannot, however, rule out that even in the electrotonic compact neurons at P6-7 the increase in SEPSC frequency is caused by a redistribution of the same number of excitatory inputs causing more EPSCs to be detected somatically. Initial frequencies of $S E P S C$ before blocking of $\mathrm{GABA}_{A}$ receptors were again increased in an/an compared to wild-type neurons (Fig 7F; $p=0.04$, ANOVA-RM-B). Notably, the excitatory charge transfers $\left(\mathrm{Q}_{\mathrm{T}+/+}=151.0 \pm 27.6 \mathrm{fC}, \mathrm{n}=24 \mathrm{vs}\right.$. $\mathrm{QT}_{\mathrm{Tan} / \mathrm{an}}=115.2 \pm 16.3 \mathrm{fC}, \mathrm{n}$ $=22, p=0.3$, ANOVA-RM-B) including mEPSC frequencies $(p=0.6)$, quantal mEPSC amplitudes $\left(I_{+/+}=6.7 \pm 0.9 \mathrm{pA}, \mathrm{n}=24 \mathrm{vs} . I_{\mathrm{an} / \mathrm{an}}=5.4 \pm 0.8 \mathrm{pA}, \mathrm{n}=22, \mathrm{p}=0.5\right)$ and $\mathrm{mEPSC}$ kinetics (decay: $\tau_{+/+}=4.8 \pm 0.3 \mathrm{~ms}, \mathrm{n}=24$ vs. $\tau_{a n / a n}=4.2 \pm 0.2 \mathrm{~ms}, \mathrm{n}=22, \mathrm{p}=0.2$, all ANOVA- 
RM-B) did not differ between neurons from +/+ and an/an animals after blocking inhibition.

293 Neuronal membrane capacitance $\left(\mathrm{C}_{+/+}=70.8 \pm 4.0 \mathrm{pF}\right.$ vs. $\mathrm{C}_{a n / a n}=84.8 \pm 9.8 \mathrm{pF}, \mathrm{p}<0.09$, $294 \mathrm{MWU})$ and amplitude density $\left(/ / C_{+/+}=0.088 \pm 0.010 \mathrm{pA} / \mathrm{pF}, \mathrm{n}=24 \mathrm{vs} . \mathrm{I} / C_{a n / a n}=0.065 \pm 0.010\right.$ $\mathrm{pA}, \mathrm{n}=22, \mathrm{p}=0.51$, ANOVA-RM-B) were comparable in $+/+$ and an/an neurons. Together these results suggest that the elevated excitatory drive at the soma detected in an/an mice is related to reduced inhibitory $\mathrm{GABA}_{\mathrm{A}}$ mediated transmission.

\section{Discussion}

Reduced brain size in patients with MCPH has been attributed to an abnormal proliferation of neural progenitors. Here we show that Cdk5rap2 also regulates the differentiation of neocortical neurons and the establishment of the neocortical circuit.

We demonstrate that the profound developmental reduction in brain size, cortical thickness and neuron numbers in the an/an mouse model of MCPH3 (Lizarraga et al., 2010) persists into adulthood (Fig 1). Brain size in itself does not necessarily imply dysfunctionality. Therefore, we investigated whether the malfunction of microcephaly-associated protein Cdk5rap2 results in additional cellular and functional defects that contribute to the neurologic phenotype. Perhaps our most striking finding is that the Cdk5rap2 mutation impacts the establishment and function of neocortical circuits, whilst pyramidal cell fate specification and cortical layering remain grossly unaltered (Fig 2). In particular, an/an mice are distinguished by an enhanced excitatory drive of neocortical pyramidal neurons during synaptogenesis and in adulthood. We performed multiple experiments to further dissect the underlying mechanism: 1) On the in vitro level of individual isolated neurons neither morphological nor physiological differences between neocortical neurons of an/an mice and their wild-type litters were present (Fig 5 and 6). This finding suggests a dysfunction developing network (including astrocytes) rather than mere cell autonomous mechanisms. 2) In ex-vivo slices from adult an/an mice we found simplified dendritic arbors with increased thin "immature" spines to be accompanied by an increase in both intrinsic excitability and (extrinsic) excitatory drive on single layer $2 / 3$ pyramidal neurons. 3) To address the question whether the increase in excitatory drive is a secondary effect, i.e., results from increased intrinsic excitability, we investigated layer $2 / 3$ neurons at an early stage of synaptogenesis. The overall increased excitatory drive in the 
mutants seems of primary synaptic origin, since the increased excitatory drive was not accompanied by a change in intrinsic excitability (Fig 4). The increased excitatory drive was accompanied by reduced inhibition (Fig 6). 4) In line with the electrophysiological data, we detected an increase overall number of excitatory synapses and a reduced number of inhibitory synapses in the cortex (Fig 4 and 6). This imbalance in the number of excitatory to inhibitory synapses on a morphologic level in the cortex, however, does not specifically pinpoint the finding to pyramidal neurons. 5) Addressing the role of inhibition in the pathomechanism of $\mathrm{MCPH}$, we found that blocking of GABAergic inhibition levels the excitatory drive of pyramidal neurons of an/an and wild-type littermates (Fig 7), arguing that the increased excitatory drive is related to a primary lack of inhibition. We cannot exclude a contribution of astrocytic malfunction, although at P6-7 no obvious morphological differences were detected (Fig S4). Altogether, we conclude that the increase in excitability is due to a shift in the balance of excitation and inhibition and that the predominant effect of Cdk5Rap2 mutation on the network level is loss of GABAergic tone onto pyramidal neurons.

Reduced inhibition might result either from a decrease in interneuron number or from a failure of interneurons to integrate into functional networks for instances by an impaired ability to form functional inhibitory synapses or both. We favor decreased inhibitory synapse formation as primary cause at early stages (Fig 6) putatively resulting in reduced interneuron density at later stages (Fig S3). Inhibitory inputs originate from interneurons that play an important regulatory role in brain development (Cossart, 2011) and migrate tangentially from the ganglionic eminence into the cortical plate to integrate into local circuits (Guo and Anton, 2014). Concurrently, Cdk5rap2 is highly expressed in the neocortex during neurogenesis and neuronal differentiation (Issa et al., 2013a), but present at lower levels during synaptogenesis that completes around P21. Loss of Cdk5rap2 prematurely shifts symmetric to asymmetric cell division leading to the earlier generation of postmitotic neurons (Buchman et al., 2010). This might impair the proper integration of interneurons into neocortical circuits on a spatio-temporal level and lead to increased interneuron death (Tuncdemir et al., 2016). Our results pointing to an impaired inhibition fit to the actual view on the importance of interneurons during neocortical development. Interneurons are critical for the integration and transmission of incoming synaptic inputs that drive maturation (Kilb, 2012), since functional GABAergic connections regulate 
network connectivity and excitation of pyramidal neurons (Isaacson and Scanziani, 2011). At early stages of cortical development, i.e. when neurons assume their positions and begin to mature, GABAergic inputs are required for the proper development of dendritic arbors and excitatory synaptic inputs (Maric et al., 2001; Wang and Kriegstein, 2009; 2008). Aberrant synaptic connections may lead to excessive dendritic pruning contributing to the observed simplified dendritic arbor. Thus, our findings of reduced dendritic complexity and reduced inhibition are in line with these previous reports.

Maturation of inhibitory synaptic contacts on the soma of somatosensory neurons, in turn, depends on proper circuit function because it is impaired upon deficits in early activity or sensory experience (Chattopadhyaya et al., 2004; Jiao et al., 2006; Xue et al., 2014). Notably, in a previous study on adult neocortical layer 2/3 pyramidal neurons (Schuster et al., 2015) we did not detect an increase in EPSC frequency after blocking inhibition. This supports the view that during early synaptogenesis in (wild-type) mice GABA release results in more ambient GABA and suggest that this developmental regulation is impaired in an/an mice. Since cortical processing relies on the fine-tuned interplay between excitation and inhibition, healthy brains exhibit a tight control of E/I ratio in all cortical areas even after perturbations (House et al., 2011; Xue et al., 2014). This control is usually ensured by several regulators of E/l adjustment (House et al., 2011; Lin et al., 2008; Rico and Marín, 2011; Xue et al., 2014). Our results in Cdk5rap2 mutants argue for an impaired E/I set point regulation as putatively caused by improper expression or targeting of molecules that control synaptic specificity. In line, our results of reduced number of inhibitory contacts while excitatory synapses and EPSC frequency was increased in an/an are mimicked when PSD95 amount was increased experimentally (Prange et al., 2004). Alternatively, inhibitory synaptogenesis might be regulated without E/l balance compensation as shown for Npas4 (Lin et al., 2008).

Transient networks involve specific types of interneurons in deep and superficial layers of the neocortex (Lim et al., 2018) and the 2 most prevalent early born interneuron populations are $\mathrm{SST}^{+}$and $\mathrm{PV}^{+}$, both generated in the MGE (Rudy et al., 2011). Since $\mathrm{PV}^{+}$neurons largely synapse on the soma of pyramidal neurons (Buhl et al., 1994) and are easy to recruit (Lazarus and Huang, 2011) they might represent a major source of early mIPSCs (Soltesz et al., 1995). $\mathrm{PV}^{+}$neurons that do not fulfill their inhibitory role might contribute to cognitive deficits (Marín, 

2012) due to perturbed perisomatic and axo-axonic inhibition. This might lead to impaired oscillatory activity in the $\gamma$-frequency range $(30-80 \mathrm{~Hz}$, (Draguhn and Buzsáki, 2004)), disturbed perisomatic feed-forward inhibition and therewith-reduced temporal precision of signal transduction in pyramidal neurons (Pouille and Scanziani, 2001) and misguided activity flow in local circuits (Xiang et al., 1998). However, synapses of $\mathrm{PV}^{+}$neurons (on pyramidal neurons and between $\mathrm{PV}^{+}$) appear only at the end of the first postnatal week (Pangratz-Fuehrer and Hestrin, 2011) and might therefore contribute marginally to the observed effects. For the GABAergic synapses that are present before that (Luhmann and Prince, 1991), SST+ provide a putative source (Takesian and Hensch, 2013). The loss or disturbance of SST+ may cause dysfunctional early transient networks and therewith impair the maturation of other interneurons as $\mathrm{PV}^{+}$basket cells (Tuncdemir et al., 2016). It is also conceivable that a SST+ neuronal loss / dysfunction would lead to disturbed oscillatory activity in the $\beta$-frequency range $(15-30 \mathrm{~Hz}$, (Draguhn and Buzsáki, 2004)).

Regardless of the cellular source, GABA reduction in the extracellular space might influence neuronal development by impairing: a) neuronal migration in the embryonic cortex (López Bendito et al., 2003), b) settlement of interneurons in the cortical plate (Bortone and Polleux, 2009), c) formation of inhibitiory synapses (Oh et al., 2016) therewith setting the balance between inhibitory and excitatory synapses in early postnatal stages as foundation of later circuit development (Flores et al., 2015) and the neurogenesis of pyramidal neurons (Silva et al., 2018).

Interpreting the functional role of increased excitatory synapses is not that straightforward, given the lack of differences in excitatory drive after blocking inhibition (Fig 7). If surplus excitatory synapses are on pyramidal neurons, they might be immature and silent. If they are on interneurons, they might represent an insufficient homoeostatic mechanism to increase inhibitory drive. In general, $\mathrm{PV}+$ neurons receive strong excitatory input from pyramidal neurons across and within layers and excitatory synapse number is modulated during development (Chung et al., 2017). This modulation might influence the maturation of working memory function since $\mathrm{PV}^{+}$neurons are key intermediates in a disinhibitory circuit motif for associative learning (Kepecs and Fishell, 2014). 

arborization and spine morphogenesis in layer $2 / 3$ neocortical pyramidal neurons further 414 highlighting a connection between centrosomal biology and dendritic morphogenesis. These data are in line with the clinical finding that some $\mathrm{MCPH}$ patients suffer from hyperactivity and seizures. Since small dysregulations in E/I balance of cortical circuits, in particular due to developmental disruptions of interneuron integration (Bartolini et al., 2013), can have dramatic effects on entire cortical integration associated with the pathophysiology of neuropsychiatric (eminently in developmental) diseases (Nelson and Valakh, 2015), further studies in humans are warranted to analyze the significance of these findings for individuals with $\mathrm{MCPH}$ gene mutations.

\section{Material and methods}

\subsection{Mice}

All mouse experiments were carried out in accordance to state of Berlin rules (registration no. T0309/09). Cdk5rap2 mutant or Hertwig's anemia mice (an/an) carrying an inversion of exon 4 (leading to exon skipping; (Lizarraga et al., 2010)) were generated by crossing heterozygous (+/an) mice (C57BL/6 background; Jackson lab, stock no. 002306). Only $9.5 \%$ of the offspring carried a homozygous mutant genotype (an/an) at birth due to in utero lethality (Zaqout et al., 2017a). Most mutants die around postnatal day (P)7. Rare an/an mice surviving longer were also used for morphological studies $(n=7)$ and electrophysiological recordings $(n=5$; P30 80). Neurons were regarded as mature (Z.-W. Zhang, 2004) and none of the parameters was correlated to age (table S2). The breeding was performed during the day, the day of birth was designated as P0. Genotyping was confirmed by PCR primers for (+/+) F 5'-TC ACT GAG CTG AAG AAG GAG AA-3', R 5'-TGT CTT TCT GCC CTG ACA GT-3' and (an/an) F 5'-GC AAT CAC TAA AAT GTC CGA TT-3', R 5'-TGT CTT TCT GCC CTG ACA GT-3'

\subsection{Niss/ staining and neocortical dimension analysis}

After dissection, brains were fixed in 4\% PFA for overnight, dehydrated in an ethanol series $(50,70,85,90,100 \%)$, cleaned with xylene, and embedded in paraffin. $10 \mu \mathrm{m}$ sections were cut on a microtome and collected on Superfrost plus slides $\AA^{\circledR}$. De-paraffinized coronal brain 
sections at the level of corpus callosum and anterior commissure were incubated in $1 \%$ cresyl violet (C5042, Sigma-Aldrich, USA) in acetate-buffered solution ( $\mathrm{pH} 4.5)$ for 5 minutes. At the level of corpus callosum and anterior commissure, parietal cortical thickness was measured perpendicularly to pial surface, and neocortical area was estimated using ImageJ software.

\subsection{Golgi staining, dendritic complexity, and spine analysis}

Golgi-Cox impregnation of adult brain samples was performed as described (Zaqout and Kaindl, 2016). Briefly, brains were immersed in the impregnation solution in darkness at room temperature (RT) for 2 weeks, and transferred into tissue-protectant solution at $4{ }^{\circ} \mathrm{C}$ for 4 days. Brains were cut into $200 \mu \mathrm{m}$ sections for dendritic complexity analysis and $100 \mu \mathrm{m}$ sections for dendritic spine analysis as described previously (Schuster et al., 2015). Sections were collected on gelatin-coated slides, left to dry for two days, developed, dehydrated through ethanol series, cleared in xylol solution, and mounted in Eukitt (quick-252 hardening mounting medium; 03989, Fluka analytical, Germany). For dendritic complexity assessment, Sholl analysis (SHOLL, 1953) was performed for layer $2 / 3$ pyramidal neurons of matched $+/+$ and an/an somatosensory neocortical regions. The total intersection number of the dendritic tree with $3010-\mu \mathrm{m}$ spaced concentric circles were counted with cell counter plug-ins in ImageJ. Neurite tracer plug-in in Fiji/lmageJ was used to draw representative neurons. The number of spines was counted in $20 \mu \mathrm{m}$ long segments of secondary basal dendrites using ImageJ. Spines were classified to one of three morphological subtypes: mushroom (short neck, large bulbous end), stubby (no neck) and thin-shaped (long neck).

\subsection{Immunohistology and immunocytology}

Paraffin sections were deparaffinized, exposed to heat-mediated antigen retrieval citrate-based solution ( $\mathrm{pH}$ 6.0; $\mathrm{H}-3300$, Vector Laboratories, USA), blocked for 1 hour with $10 \%$ donkey or goat normal serum at RT, and incubated overnight with the primary antibody at RT followed by an incubation with the corresponding secondary antibodies for 2 hours at RT. The following primary antibodies were used at specified dilutions: rabbit anti-Cux1 (1:200; Santa Cruz Biotechnology, Heidelberg, Germany, sc-13024 (Issa et al., 2013a)), rat anti-Ctip2 (1:250; Abcam, Cambridge, UK, ab18465 (Issa et al., 2013a)), mouse anti-GABA (GABA, 1:100; 
472 Chemicon, Temecula CA, MAB316 (Uematsu et al., 2008)), rabbit anti-NeuN (1:200; Merck-

473 Millipore, Germany, ABN78 (Issa et al., 2013a)), guinea pig anti-vesicular glutamate transporter

4741 (VGlut1, 1:500; Merck-Millipore, Germany, AB5905 (Mitchell et al., 2012)), rabbit anti475 vesicular GABA transporter (VGat, 1:500; Merck-Millipore, Germany, AB5062P (Mitchell et al., 476 2012)), and rabbit anti-post synaptic density 95 (PSD95, 1:200; Synaptic System, Göttingen, 477 Germany, 124-002 (Schuster et al., 2015)). Secondary antibodies were used at 1:400 dilution: 478 donkey Cy3-conjugated anti-rabbit and anti-mouse IgG (Jackson ImmunoResearch, Suffolk, 479 UK), donkey Alexa Fluor® 488 conjugate anti-rat, and anti-guinea pig IgG (Invitrogen, 480 Darmstadt, Germany). Nuclei were stained with 40,6-diamidino-2-phenylindole (DAPI, 1:1000, 481 Sigma-Aldrich, USA). Neuronal cultures were prepared from cortices of P0 - P2 +/+ and an/an 482 mice and stained with vesicular glutamate transporter 1 (VGlut1; excitatory presynaptic marker; 483 green) or vesicular GABA transporter (VGat; inhibitory presynaptic marker; red). Staining of 484 microtubule network with microtubule-associated protein Map2a (white) was used to display 485 soma and dendritic tree of individual neurons and count the number of cells per view field. 486 Cultures were fixed at DIV 14-16 with 4\% PFA for 10 min and permeabilized with 1xPBS + $4870.1 \%$ Tween 20 (PBS-T). Cells were blocked with PBS-T containing $5 \%$ donkey serum for $1 \mathrm{~h}$, 488 before applying the primary antibody overnight at $4^{\circ} \mathrm{C}$ (anti-Map2a, Millipore, anti-VGlut1 and 489 anti-VGat, Synaptic Systems). The secondary fluorophore-conjugated antibody was incubated 490 for $1 \mathrm{~h}$ at RT. All antibodies used in this paper are well established and were previously applied 491 by others and us on mouse tissue. In addition, negative control staining experiments including 492 the application of the secondary antibody only have been performed (Fig S1).

\subsection{Electrophysiology on ex-vivo brain slices}

495 Slices of mouse brains (P6/7 and adult) were used for ex-vivo recordings. Mice were 496 decapitated, brains removed, and transferred to ice-cold artificial cerebrospinal fluid (ACSF) containing $85 \mathrm{mM} \mathrm{NaCl}, 26 \mathrm{mM} \mathrm{NaHCO}_{3}, 2.5 \mathrm{mM} \mathrm{KCl}, 1 \mathrm{mM} \mathrm{NaH}_{2} \mathrm{PO}_{4}, 0.5 \mathrm{mM} \mathrm{CaCl}_{2}, 7 \mathrm{mM}$ $\mathrm{MgCl}_{2}, 50 \mathrm{mM}$ sucrose, and $10 \mathrm{mM}$ glucose (290-310 mOsm). Coronal slices (300 $\mu \mathrm{m}$ thick) containing somatosensory cortex were cut on a Leica VT1200S (Leica Microsystems, Germany). Slices recovered for 30 minutes at $34{ }^{\circ} \mathrm{C}$ and were kept at room temperature afterwards. Somatic whole-cell recordings were performed in a submerged recording chamber 
perfused with ACSF containing $117 \mathrm{mM} \mathrm{NaCl}, 3.5 \mathrm{mM} \mathrm{KCl}, 1.25 \mathrm{mM} \mathrm{NaH}_{2} \mathrm{PO} 4,2 \mathrm{mM} \mathrm{MgSO}_{4}$ or $\mathrm{MgCl}_{2}, 26 \mathrm{mM} \mathrm{NaHCO} 3,10 \mathrm{mM}$ glucose, and $2 \mathrm{mM} \mathrm{CaCl}$. All ACSF solutions were constantly gassed with $95 \% \mathrm{O}_{2} / 5 \% \mathrm{CO}_{2}$, osmolarity was between 290 and $305 \mathrm{mosmol} / \mathrm{l}$, and experiments were performed at $32-34^{\circ} \mathrm{C}$. Pyramidal neurons were visually identified in layer 2/3 using an upright microscope equipped with infrared differential interference contrast optics (Axioskop FS2; Zeiss or Olympus BX51, Germany). Whole-cell patch clamp recordings were conducted with pipettes (tip resistance 3-5 M ) filled with intracellular solution containing 120 $\mathrm{mM}$ K-gluconate, $10 \mathrm{mM} \mathrm{KCl}, 10 \mathrm{mM}$ Na-phosphocreatine, $1 \mathrm{mM} \mathrm{MgCl}$, $1 \mathrm{mM} \mathrm{CaCl}$, $11 \mathrm{mM}$

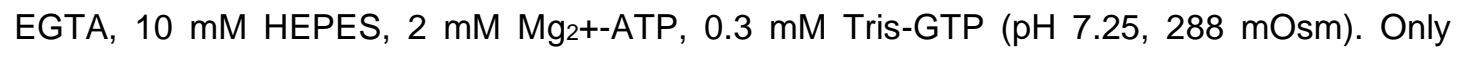
neurons with resting potentials below $-65 \mathrm{mV}$ and spiking characteristics of pyramidal neurons were included in the analysis. Input resistance was calculated with a linear fit of the current clamp generated I-V plot in close vicinity of the resting potential. Intersection of the linear regression of the F-I relationship (estimated in the linear range) and abscissa roughly approximated the rheobase. Postsynaptic currents were recorded in voltage clamp at a holding potential of $-60 \mathrm{mV}$. Under these conditions, most spontaneous postsynaptic events are mediated by activation of glutamatergic, AMPA receptor mediated currents (Schuster et al., 2015). Miniature postsynaptic currents (mPSCs) were recorded in the presence of $0.5-1 \mu \mathrm{M}$ tetrodotoxin (TTX). mEPSCs were analyzed in presence of bicuculline $(20 \mu \mathrm{M})$ while mIPSC were analyzed in presence of $10 \mu \mathrm{M} \mathrm{CNQX}$ and $25 \mu \mathrm{M}$ D-AP5 and with $\mathrm{KCl}$-based internal solutions (all Tocris Bioscience). Data from patch-clamp recordings were collected with an EPC-10 double amplifier (HEKA, Germany), digitized (10 kHz, after Bessel filtering at $2.9 \mathrm{kHz}$ ), and stored using PatchMaster software (HEKA). Series resistance (Rs) was monitored throughout experiments; neurons were rejected if $R_{S}$ was $>20 \mathrm{M} \Omega$ or varied $> \pm 30 \%$. No Rs compensation was used. Liquid junction potentials were not corrected for. Synaptic events were detected offline using the Mini Analysis Program (Synaptosoft Inc., USA) and a threshold of 3.5 times noise (standard deviation of regions without manually detectable postsynaptic currents). All events were visually counterchecked. As integrated measure the total charge transfer was calculated from the equation: $Q=f \times$ Qpscs, where $f$ is the frequency $\left(s^{-1}\right)$, and QPSCs is the average charge transfer for each PSC (Ataka and Gu, 2006). Paired EPSCs (50 ms interval) were elicited by square pulse $(100 \mu \mathrm{s})$ stimulation of the slice $50-100 \mu \mathrm{m}$ lateral 
of the recording electrode at the border between layer $2 / 3$ and 4 with a concentric tungsten electrode (TM33CCINS, WPI, USA). All compounds used were purchased from Sigma-Aldrich, Germany unless stated otherwise.

\subsection{Electrophysiology on dissociated cell cultures}

Autaptic and continental primary neuronal cultures from the cortices were prepared from newborn (P0-P2) mice, and neurons were plated on astrocyte feeder layer from cortices of nonmutated C57/B16 mouse pups (P0-P2; prepared 2 weeks before plating the neurons) as previously described (Wu et al., 2015). Briefly, cortices were removed, enzymatically and mechanically dissociated. Neurons were cultured in Neurobasal-A media containing B-27 Supplement, $10 \mathrm{IU} / \mathrm{ml}$ penicillin, $1 \mathrm{~g} / \mathrm{ml}$ streptomycin, and $2 \mathrm{mM} \mathrm{L}$-alanyl-L-glutamine. The seeding density for continental cultures was $1.35 \times 10^{4} \mathrm{cells} / \mathrm{cm}^{2}$. Cultures with different genotypes were generated from siblings that were treated identically during culturing and incubated at $37{ }^{\circ} \mathrm{C}$ with $5 \% \mathrm{CO}_{2}$. Whole cell voltage-clamp recordings from autaptic cortical excitatory neurons were obtained between days in vitro (DIV) 14-16 at RT. Recordings and analysis of data were done as previously described (Wu et al., 2015). Extracellular solution contained in mM: $140 \mathrm{NaCl}, 2.4 \mathrm{KCl}, 10 \mathrm{HEPES}, 10$ glucose, $2 \mathrm{CaCl}_{2}$, and $4 \mathrm{MgCl}_{2}$. The pipette internal solution contained in mM: $136 \mathrm{KCl}$, 17.8 HEPES, 1 EGTA, $4.6 \mathrm{MgCl}_{2}$, 4 ATP-Na2, 0.3 GTP-Na2, 12 creatine phosphate, and $50 \mathrm{U} / \mathrm{ml}$ phosphocreatine kinase. Both extracellular and internal solutions were adjusted to $\mathrm{pH} 7.4$ and osmolarity of $\sim 300$ mOsm. Borosilicate glass pipettes had a resistance of 3-4 M $\Omega$. Recordings were performed with a MultiClamp 700B amplifier, and data were acquired with Clampex 10.0 (Molecular Devices). To verify glutamatergic responses in autaptic cultures, $3 \mathrm{mM}$ kynurenic acid was applied to the extracellular solution. Sucrose solution ( $500 \mathrm{mM}$ added to external solution) was applied for 5 $S$ to assess the size of the readily releasable pool (RRP; (Rosenmund and Stevens, 1996)). Evoked EPSCs were recorded after somatic depolarization from -70 to $0 \mathrm{mV}$ for $2 \mathrm{~ms}$. Vesicular release probability (PVr) was determined by calculating the EPSC charge divided by the RRP charge of individual neurons. Spontaneous release was determined as mEPSC and was recorded for $60 \mathrm{~s}$ at $-70 \mathrm{mV}$. To subtract background noise, recording was performed with the application of $3 \mathrm{mM}$ kynurenic acid for the same duration. Traces were filtered at $1 \mathrm{kHz}$, 
and events were detected by using a template-based algorithm in AxoGraphX. Data was collected from two independent cultures.

\subsection{Imaging}

Brightfield images of Nissl-stained brain sections and Golgi-stained dendritic spines were taken by Olympus BX60 microscope equipped with an Axiocam MRc Zeiss camera and Axiovision 4.8 software (Zeiss, Göttingen, Germany). For studying dendritic arborization, 1- $\mu \mathrm{m}$-spaced Zstack brightfield images were taken by an Olympus IX81 microscope equipped with an F View II (sw) camera (Soft Imaging System GmbH, Münster, Germany). Fluorescent images of layer markers were taken by Olympus BX51 microscope by an Intas camera and Magnafire 2.1B software (Olympus, Hamburg, Germany). Fluorescent images of synaptic markers were taken by an Ism5exciter Zeiss confocal microscope with the software Zen (version 2009, Zeiss, Jena, Germany). Fluorescent images of dissociated cell culture were taken with an Olympus IX81 epifluorescent microscope. All images were processed using Adobe Photoshop CS6 version 13.0x64 and Fiji/ImageJ software.

\subsection{Statistical analysis}

For in-vivo parietal cortical thickness, neocortical area, cortical layers, Scholl analysis, and spine density statistics, two-tailed Student's t-tests (TT) were applied. Statistics of ex-vivo brain slices electrophysiology were performed using Origin8.5 (OriginLab, USA). For normally distributed datasets (Shapiro-Wilk test) TT was used. In the case of significant deviations from normal distribution $(p \leq 0.05)$ the non-parametric Mann-Whitney-U test $(M W U)$ was used. The frequency of mEPSCs before and after application of bicuculline was analyzed with two way repeated measures ANOVA and post hoc Bonferroni multiple-comparison tests (ANOVA-RMB). Data of dissociated cell cultures were first tested for a Gaussian distribution with D'Agostino and Pearson omnibus normality test. If data were normally distributed, one-way ANOVA followed by Bonferroni multiple-comparison tests were performed. Otherwise, nonparametric Kruskal-Wallis test followed by Dunn multiple comparison tests were used. 


\section{Authors' contributions}

AMK, US, and CR were responsible for project conception. AMK, SZ, KB and US wrote the manuscript. SZ, KB, YJW, SO, US, LLB, MR and NK performed and analyzed the experiments.

All authors read, revised, and approved the final manuscript.

\section{Acknowledgments}

The authors thank Victor Tarabykin, Paraskevi Bessa, Pina Knauff, Jutta Schüler, Gisela Stoltenburg, Jessica Fassbender, Susanne Kosanke, Magdalena John, Julia König and Claudia Pallasch for discussions and/or technical assistance as well as Janna Lehnhoff and Noah L. Döhne for conducting some of the patch clamp experiments. The German Research Foundation (DFG, SFB665), the Helmholtz Association the Berlin Institute of Health (BIH), the

German Academic Exchange Service (DAAD), and the Charité - Universitätsmedizin Berlin, supported this work.

\section{Conflicts of Interest}

The authors declare that they have no competing interests.

\section{References}

Ataka, T., Gu, J.G., 2006. Relationship between tonic inhibitory currents and phasic inhibitory activity in the spinal cord lamina II region of adult mice. Mol Pain 2, 36. doi:10.1186/1744-8069-2-36

Barrera, J.A., Kao, L.-R., Hammer, R.E., Seemann, J., Fuchs, J.L., Megraw, T.L., 2010. CDK5RAP2 regulates centriole engagement and cohesion in mice. Dev. Cell 18, 913926. doi:10.1016/j.devcel.2010.05.017

Bartolini, G., Ciceri, G., Marín, O., 2013. Integration of GABAergic interneurons into cortical cell assemblies: lessons from embryos and adults. Neuron 79, 849-864. doi:10.1016/j.neuron.2013.08.014

Bond, J., Roberts, E., Springell, K., Lizarraga, S.B., Lizarraga, S., Scott, S., Higgins, J., Hampshire, D.J., Morrison, E.E., Leal, G.F., Silva, E.O., Costa, S.M.R., Baralle, D., Raponi, M., Karbani, G., Rashid, Y., Jafri, H., Bennett, C., Corry, P., Walsh, C.A., Woods, C.G., 2005. A centrosomal mechanism involving CDK5RAP2 and CENPJ controls brain size. Nat Genet 37, 353-355. doi:10.1038/ng1539

Bortone, D., Polleux, F., 2009. KCC2 expression promotes the termination of cortical interneuron migration in a voltage-sensitive calcium-dependent manner. Neuron 62, 5371. doi:10.1016/j.neuron.2009.01.034

Buchman, J.J., Tseng, H.-C., Zhou, Y., Frank, C.L., Xie, Z., Tsai, L.-H., 2010. Cdk5rap2 interacts with pericentrin to maintain the neural progenitor pool in the developing neocortex. Neuron 66, 386-402. doi:10.1016/j.neuron.2010.03.036

Buhl, E.H., Halasy, K., Somogyi, P., 1994. Diverse sources of hippocampal unitary inhibitory postsynaptic potentials and the number of synaptic release sites. Nature 368, 823-828. doi:10.1038/368823a0 
Chattopadhyaya, B., Di Cristo, G., Higashiyama, H., Knott, G.W., Kuhlman, S.J., Welker, E., Huang, Z.J., 2004. Experience and activity-dependent maturation of perisomatic GABAergic innervation in primary visual cortex during a postnatal critical period. Journal of Neuroscience 24, 9598-9611. doi:10.1523/JNEUROSCI.1851-04.2004

Chung, D.W., Wills, Z.P., Fish, K.N., Lewis, D.A., 2017. Developmental pruning of excitatory synaptic inputs to parvalbumin interneurons in monkey prefrontal cortex. Proc Natl Acad Sci USA 114, E629-E637. doi:10.1073/pnas.1610077114

Cossart, R., 2011. The maturation of cortical interneuron diversity: how multiple developmental journeys shape the emergence of proper network function. Curr Opin Neurobiol 21, 160-168. doi:10.1016/j.conb.2010.10.003

Dailey, M.E., Smith, S.J., 1996. The Dynamics of Dendritic Structure in Developing Hippocampal Slices. J Neurosci 16, 2983-2994.

del CASTILLO, J., KATZ, B., 1954. Quantal components of the end-plate potential. The Journal of Physiology 124, 560-573.

DiStasio, A., Driver, A., Sund, K., Donlin, M., Muraleedharan, R.M., Pooya, S., Kline-Fath, B., Kaufman, K.M., Prows, C.A., Schorry, E., Dasgupta, B., Stottmann, R.W., 2017. Copb2 is essential for embryogenesis and hypomorphic mutations cause human microcephaly. Hum. Mol. Genet. 26, 4836-4848. doi:10.1093/hmg/ddx362

Draguhn, A., Buzsáki, G., 2004. Neuronal oscillations in cortical networks. Science 304, 1926-1929. doi:10.1126/science.1099745

Fish, J.L., Kosodo, Y., Enard, W., Pääbo, S., Huttner, W.B., 2006. Aspm specifically maintains symmetric proliferative divisions of neuroepithelial cells. Proc Natl Acad Sci USA 103, 10438-10443. doi:10.1073/pnas.0604066103

Flores, C.E., Nikonenko, I., Mendez, P., Fritschy, J.-M., Tyagarajan, S.K., Muller, D., 2015. Activity-dependent inhibitory synapse remodeling through gephyrin phosphorylation. Proc Natl Acad Sci USA 112, E65-72. doi:10.1073/pnas.1411170112

Fong, K.-W., Choi, Y.-K., Rattner, J.B., Qi, R.Z., 2008. CDK5RAP2 is a pericentriolar protein that functions in centrosomal attachment of the gamma-tubulin ring complex. Mol Biol Cell 19, 115-125. doi:10.1091/mbc.E07-04-0371

Guo, J., Anton, E.S., 2014. Decision making during interneuron migration in the developing cerebral cortex. Trends Cell Biol. 24, 342-351. doi:10.1016/j.tcb.2013.12.001

Hassan, M.J., Khurshid, M., Azeem, Z., John, P., Ali, G., Chishti, M.S., Ahmad, W., 2007. Previously described sequence variant in CDK5RAP2 gene in a Pakistani family with autosomal recessive primary microcephaly. BMC Med. Genet. 8, 58. doi:10.1186/14712350-8-58

House, D.R.C., Elstrott, J., Koh, E., Chung, J., Feldman, D.E., 2011. Parallel regulation of feedforward inhibition and excitation during whisker map plasticity. Neuron 72, 819-831. doi:10.1016/j.neuron.2011.09.008

Isaacson, J.S., Scanziani, M., 2011. How inhibition shapes cortical activity. Neuron 72, 231243. doi:10.1016/j.neuron.2011.09.027

Issa, L., Kraemer, N., Rickert, C.H., Sifringer, M., Ninnemann, O., Stoltenburg-Didinger, G., Kaindl, A.M., 2013a. CDK5RAP2 expression during murine and human brain development correlates with pathology in primary autosomal recessive microcephaly. Cereb Cortex 23, 2245-2260. doi:10.1093/cercor/bhs212

Issa, L., Mueller, K., Seufert, K., Kraemer, N., Rosenkotter, H., Ninnemann, O., Buob, M., Kaindl, A.M., Morris-Rosendahl, D.J., 2013b. Clinical and cellular features in patients with primary autosomal recessive microcephaly and a novel CDK5RAP2 mutation. Orphanet J Rare Dis 8, 59. doi:10.1186/1750-1172-8-59

Jiao, Y., Zhang, C., Yanagawa, Y., Sun, Q.-Q., 2006. Major effects of sensory experiences on the neocortical inhibitory circuits. Journal of Neuroscience 26, 8691-8701. doi:10.1523/JNEUROSCI.2478-06.2006

Kadir, R., Harel, T., Markus, B., Perez, Y., Bakhrat, A., Cohen, I., Volodarsky, M., FeintseinLinial, M., Chervinski, E., Zlotogora, J., Sivan, S., Birnbaum, R.Y., Abdu, U., Shalev, S., Birk, O.S., 2016. ALFY-Controlled DVL3 Autophagy Regulates Wnt Signaling, Determining Human Brain Size. PLoS Genet 12, e1005919. doi:10.1371/journal.pgen.1005919

Kaindl, A.M., Passemard, S., Kumar, P., Kraemer, N., Issa, L., Zwirner, A., Gerard, B., Verloes, A., Mani, S., Gressens, P., 2010. Many roads lead to primary autosomal recessive microcephaly. Prog Neurobiol 90, 363-383. doi:10.1016/j.pneurobio.2009.11.002 
Kepecs, A., Fishell, G., 2014. Interneuron cell types are fit to function. Nature 505, 318-326. doi:10.1038/nature12983

Kilb, W., 2012. Development of the GABAergic system from birth to adolescence. Neuroscientist 18, 613-630. doi:10.1177/1073858411422114

Kim, A.H., Puram, S.V., Bilimoria, P.M., Ikeuchi, Y., Keough, S., Wong, M., Rowitch, D., Bonni, A., 2009. A centrosomal Cdc20-APC pathway controls dendrite morphogenesis in postmitotic neurons. Cell 136, 322-336. doi:10.1016/j.cell.2008.11.050

Kraemer, N., Issa, L., Hauck, S.C.R., Mani, S., Ninnemann, O., Kaindl, A.M., 2011. What's the hype about CDK5RAP2? Cell Mol Life Sci 68, 1719-1736. doi:10.1007/s00018-0110635-4

Kraemer, N., Ravindran, E., Zaqout, S., Neubert, G., Schindler, D., Ninnemann, O., Gräf, R., Seiler, A.E.M., Kaindl, A.M., 2015. Loss of CDK5RAP2 affects neural but not non-neural mESC differentiation into cardiomyocytes. Cell Cycle 14, 2044-2057. doi:10.1080/15384101.2015.1044169

Lazarus, M.S., Huang, Z.J., 2011. Distinct maturation profiles of perisomatic and dendritic targeting GABAergic interneurons in the mouse primary visual cortex during the critical period of ocular dominance plasticity. J Neurophysiol 106, 775-787. doi:10.1152/jn.00729.2010

Lim, L., Mi, D., Llorca, A., Marín, O., 2018. Development and Functional Diversification of Cortical Interneurons. Neuron 100, 294-313. doi:10.1016/j.neuron.2018.10.009

Lin, Y., Bloodgood, B.L., Hauser, J.L., Lapan, A.D., Koon, A.C., Kim, T.-K., Hu, L.S., Malik, A.N., Greenberg, M.E., 2008. Activity-dependent regulation of inhibitory synapse development by Npas4. Nature 455, 1198-1204. doi:10.1038/nature07319

Lizarraga, S.B., Margossian, S.P., Harris, M.H., Campagna, D.R., Han, A.-P., Blevins, S., Mudbhary, R., Barker, J.E., Walsh, C.A., Fleming, M.D., 2010. Cdk5rap2 regulates centrosome function and chromosome segregation in neuronal progenitors. Development 137, 1907-1917. doi:10.1242/dev.040410

López Bendito, G., Luján, R., Shigemoto, R., Ganter, P., Paulsen, O., Molnár, Z., 2003. Blockade of $\mathrm{GABA}(\mathrm{B})$ receptors alters the tangential migration of cortical neurons. Cereb Cortex 13, 932-942.

Luhmann, H.J., Prince, D.A., 1991. Postnatal maturation of the GABAergic system in rat neocortex. J Neurophysiol 65, 247-263. doi:10.1152/jn.1991.65.2.247

Maric, D., Liu, Q.Y., Maric, I., Chaudry, S., Chang, Y.H., Smith, S.V., Sieghart, W., Fritschy, J.M., Barker, J.L., 2001. GABA expression dominates neuronal lineage progression in the embryonic rat neocortex and facilitates neurite outgrowth via $\mathrm{GABA}(\mathrm{A})$ autoreceptor/Cl- channels. Journal of Neuroscience 21, 2343-2360.

Marín, O., 2012. Interneuron dysfunction in psychiatric disorders. Nature Publishing Group 13, 107-120. doi:10.1038/nrn3155

Matsuzaki, M., Ellis-Davies, G.C., Nemoto, T., Miyashita, Y., lino, M., Kasai, H., 2001. Dendritic spine geometry is critical for AMPA receptor expression in hippocampal CA1 pyramidal neurons. Nat Neurosci 4, 1086-1092. doi:10.1038/nn736

Mitchell, N., Petralia, R.S., Currier, D.G., Wang, Y.-X., Kim, A., Mattson, M.P., Yao, P.J., 2012. Sonic hedgehog regulates presynaptic terminal size, ultrastructure and function in hippocampal neurons. Journal of Cell Science 125, 4207-4213. doi:10.1242/jcs.105080

Moawia, A., Shaheen, R., Rasool, S., Waseem, S.S., Ewida, N., Budde, B., Kawalia, A., Motameny, S., Khan, K., Fatima, A., Jameel, M., Ullah, F., Akram, T., Ali, Z., Abdullah, U., Irshad, S., Höhne, W., Noegel, A.A., Al-Owain, M., Hörtnagel, K., Stöbe, P., Baig, S.M., Nürnberg, P., Alkuraya, F.S., Hahn, A., Hussain, M.S., 2017. Mutations of KIF14 cause primary microcephaly by impairing cytokinesis. Ann. Neurol. 82, 562-577. doi:10.1002/ana.25044

Nair, D., Hosy, E., Petersen, J.D., Constals, A., Giannone, G., Choquet, D., Sibarita, J.-B., 2013. Super-resolution imaging reveals that AMPA receptors inside synapses are dynamically organized in nanodomains regulated by PSD95. Journal of Neuroscience 33, 13204-13224. doi:10.1523/JNEUROSCI.2381-12.2013

Nelson, S.B., Valakh, V., 2015. Excitatory/Inhibitory Balance and Circuit Homeostasis in Autism Spectrum Disorders. Neuron 87, 684-698. doi:10.1016/j.neuron.2015.07.033

Oh, W.C., Lutzu, S., Castillo, P.E., Kwon, H.-B., 2016. De novo synaptogenesis induced by GABA in the developing mouse cortex. Science 353, 1037-1040. doi:10.1126/science.aaf5206

Pangratz-Fuehrer, S., Hestrin, S., 2011. Synaptogenesis of electrical and GABAergic 
synapses of fast-spiking inhibitory neurons in the neocortex. Journal of Neuroscience 31, 10767-10775. doi:10.1523/JNEUROSCI.6655-10.2011

Passemard, S., Titomanlio, L., Elmaleh, M., Afenjar, A., Alessandri, J.-L., Andria, G., de Villemeur, T.B., Boespflug-Tanguy, O., Burglen, L., Del Giudice, E., Guimiot, F., Hyon, C., Isidor, B., Mégarbané, A., Moog, U., Odent, S., Hernandez, K., Pouvreau, N., Scala, I., Schaer, M., Gressens, P., Gerard, B., Verloes, A., 2009. Expanding the clinical and neuroradiologic phenotype of primary microcephaly due to ASPM mutations. Neurology 73, 962-969. doi:10.1212/WNL.0b013e3181b8799a

Pouille, F., Scanziani, M., 2001. Enforcement of temporal fidelity in pyramidal cells by somatic feed-forward inhibition. Science 293, 1159-1163. doi:10.1126/science.1060342

Prange, O., Wong, T.P., Gerrow, K., Wang, Y.T., El-Husseini, A., 2004. A balance between excitatory and inhibitory synapses is controlled by PSD-95 and neuroligin. Proc Natl Acad Sci USA 101, 13915-13920. doi:10.1073/pnas.0405939101

Rico, B., Marín, O., 2011. Neuregulin signaling, cortical circuitry development and schizophrenia. Curr. Opin. Genet. Dev. 21, 262-270. doi:10.1016/j.gde.2010.12.010

Rosenmund, C., Stevens, C.F., 1996. Definition of the readily releasable pool of vesicles at hippocampal synapses. Neuron 16, 1197-1207.

Rudy, B., Fishell, G., Lee, S., Hjerling-Leffler, J., 2011. Three groups of interneurons account for nearly $100 \%$ of neocortical GABAergic neurons. Dev Neurobiol 71, 45-61. doi:10.1002/dneu.20853

Schuster, S., Rivalan, M., Strauss, U., Stoenica, L., Trimbuch, T., Rademacher, N., Parthasarathy, S., Lajkó, D., Rosenmund, C., Shoichet, S.A., Winter, Y., Tarabykin, V., Rosário, M., 2015. NOMA-GAP/ARHGAP33 regulates synapse development and autistic-like behavior in the mouse. Mol. Psychiatry 20, 1120-1131. doi:10.1038/mp.2015.42

SHOLL, D.A., 1953. Dendritic organization in the neurons of the visual and motor cortices of the cat. J Anat 87, 387-406.

Silva, C.G., Peyre, E., Adhikari, M.H., Tielens, S., Tanco, S., Van Damme, P., Magno, L., Krusy, N., Agirman, G., Magiera, M.M., Kessaris, N., Malgrange, B., Andrieux, A., Janke, C., Nguyen, L., 2018. Cell-Intrinsic Control of Interneuron Migration Drives Cortical Morphogenesis. Cell 172, 1063-1078.e19. doi:10.1016/j.cell.2018.01.031

Soltesz, I., Smetters, D.K., Mody, I., 1995. Tonic inhibition originates from synapses close to the soma. Neuron 14, 1273-1283.

Spruston, N., Jaffe, D.B., Williams, S.H., Johnston, D., 1993. Voltage- and space-clamp errors associated with the measurement of electrotonically remote synaptic events. J Neurophysiol 70, 781-802. doi:10.1152/jn.1993.70.2.781

Takesian, A.E., Hensch, T.K., 2013. Balancing plasticity/stability across brain development. Prog Brain Res 207, 3-34. doi:10.1016/B978-0-444-63327-9.00001-1

Tuncdemir, S.N., Wamsley, B., Stam, F.J., Osakada, F., Goulding, M., Callaway, E.M., Rudy, B., Fishell, G., 2016. Early Somatostatin Interneuron Connectivity Mediates the Maturation of Deep Layer Cortical Circuits. Neuron 89, 521-535. doi:10.1016/j.neuron.2015.11.020

Turrigiano, G., Leslie, K.R., Desai, N.S., Rutherford, L.C., Nelson, S.B., 1998. Activitydependent scaling of quantal amplitude in neocortical neurons. Nature 391, 892-896. doi:10.1038/36103

Uematsu, M., Hirai, Y., Karube, F., Ebihara, S., Kato, M., Abe, K., Obata, K., Yoshida, S., Hirabayashi, M., Yanagawa, Y., Kawaguchi, Y., 2008. Quantitative chemical composition of cortical GABAergic neurons revealed in transgenic venus-expressing rats. Cereb Cortex 18, 315-330. doi:10.1093/cercor/bhm056

Wang, D.D., Kriegstein, A.R., 2009. Defining the role of GABA in cortical development. The Journal of Physiology 587, 1873-1879. doi:10.1113/jphysiol.2008.167635

Wang, D.D., Kriegstein, A.R., 2008. GABA regulates excitatory synapse formation in the neocortex via NMDA receptor activation. Journal of Neuroscience 28, 5547-5558. doi:10.1523/JNEUROSCI.5599-07.2008

Wu, Y.-J., Tejero, R., Arancillo, M., Vardar, G., Korotkova, T., Kintscher, M., Schmitz, D., Ponomarenko, A., Tabares, L., Rosenmund, C., 2015. Syntaxin 1B is important for mouse postnatal survival and proper synaptic function at the mouse neuromuscular junctions. J Neurophysiol 114, 2404-2417. doi:10.1152/jn.00577.2015

Xiang, Z., Huguenard, J.R., Prince, D.A., 1998. Cholinergic switching within neocortical inhibitory networks. Science 281, 985-988. 
Xue, M., Atallah, B.V., Scanziani, M., 2014. Equalizing excitation-inhibition ratios across visual cortical neurons. Nature 511, 596-600. doi:10.1038/nature13321

Yoon, B.-E., Lee, C.J., 2014. GABA as a rising gliotransmitter. Front Neural Circuits 8, 141. doi:10.3389/fncir.2014.00141

Zaqout, S., Bessa, P., Krämer, N., Stoltenburg-Didinger, G., Kaindl, A.M., 2017a. CDK5RAP2 Is Required to Maintain the Germ Cell Pool during Embryonic Development. Stem Cell Reports 8, 198-204. doi:10.1016/j.stemcr.2017.01.002

Zaqout, S., Kaindl, A.M., 2016. Golgi-Cox Staining Step by Step. Frontiers in neuroanatomy 10, 38. doi:10.3389/fnana.2016.00038

Zaqout, S., Morris-Rosendahl, D., Kaindl, A.M., 2017b. Autosomal Recessive Primary Microcephaly (MCPH): An Update. Neuropediatrics 48, 135-142. doi:10.1055/s-00371601448

Zhang, X., Liu, D., Lv, S., Wang, H., Zhong, X., Liu, B., Wang, B., Liao, J., Li, J., Pfeifer, G.P., $\mathrm{Xu}, \mathrm{X} ., 2009$. CDK5RAP2 is required for spindle checkpoint function. Cell Cycle 8, 12061216. doi:10.4161/cc.8.8.8205

Zhang, Z.-W., 2004. Maturation of layer V pyramidal neurons in the rat prefrontal cortex: intrinsic properties and synaptic function. J Neurophysiol 91, 1171-1182. doi:10.1152/jn.00855.2003 

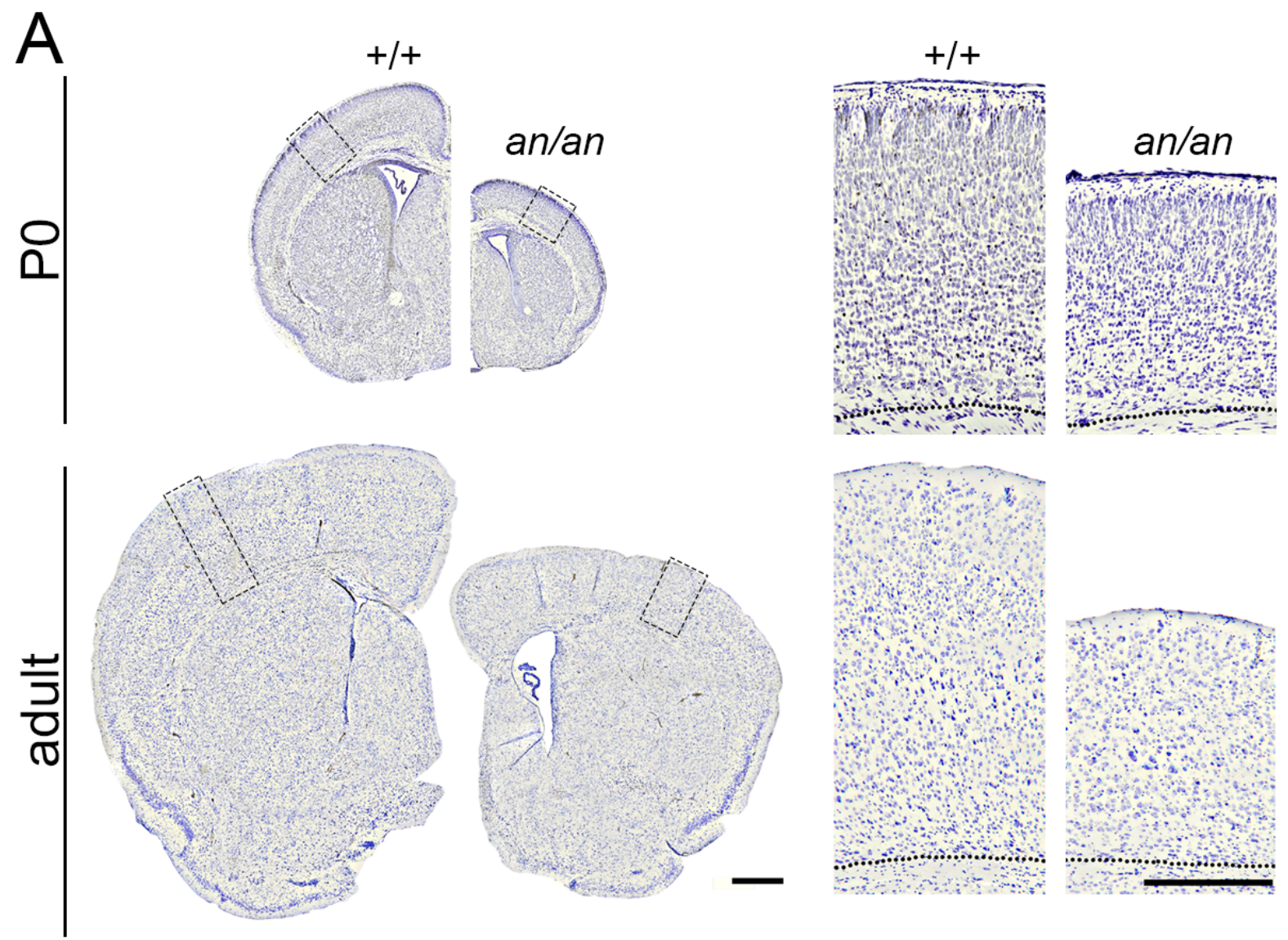

B
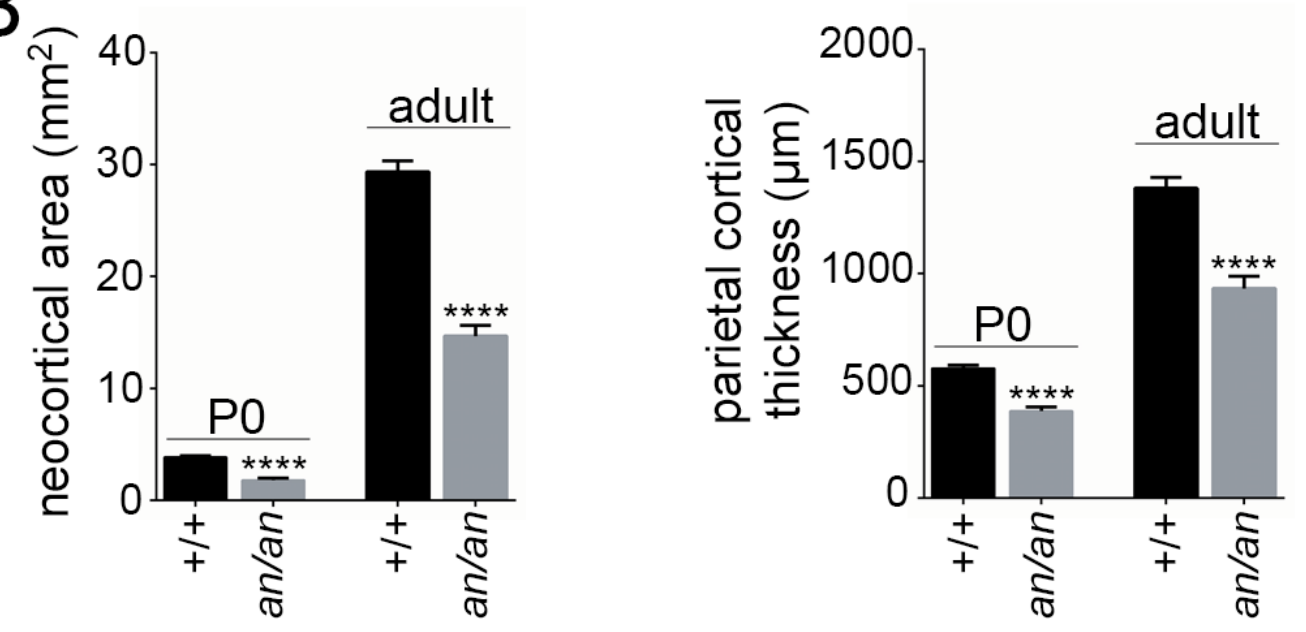

833 Fig 1. Microcephaly with pronounced cortical thinning in an/an mice. (A) Coronal brain sections 834 of $\mathrm{P} 0$ and adult littermate animals with parietal cortex sections magnified on the right side (NissI 835 staining, scale bars $500 \mu \mathrm{m}$ ). (B) Reduction of the neocortical area and parietal cortical 836 thickness in an/an mice. Throughout these graphs $\mathrm{n}=8$ animals/group and error bars indicate 837 S.E.M., TT, ${ }^{* \star} p<0.01,{ }^{* \star * *} p<0.0001$. For age as additional between subject factor see ANOVA 838 at table S1. 


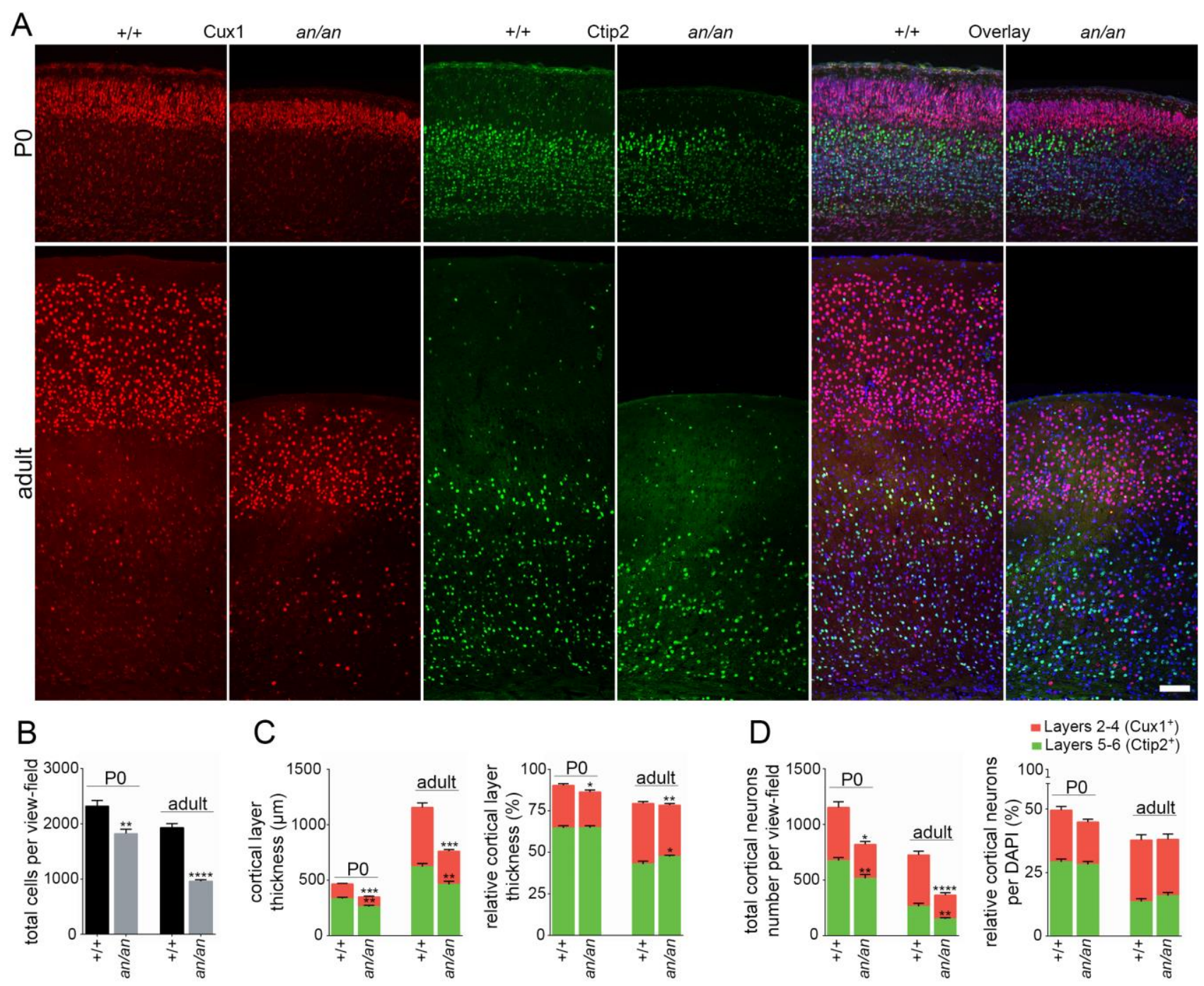

839

840 Fig 2. Preserved neocortical layer organization despite reduced thickness of upper cortical

841 layers in an/an mice. (A) Coronal brain sections of P0 and adult littermate animals stained for

842 upper layer marker Cux1 (layers 2-4) and deeper layer marker Ctip2 (layers 5-6)

843 (immunofluorescence images, scale bar $100 \mu \mathrm{m}$ ). (B) Reduction of total DAPI+ nuclei per view-

844 field in an/an mice. (C) While the Cux $1^{+}$upper layers and Ctip2+ deep layers are thinner, only

845 the relative thickness of upper layers with respect to the total cortical thickness mice was

846 reduced in an/an mice. The relative thickness of the deep layers with respect to the total cortical

847 thickness was similar. (D) Reduction of the Cux1+ and Ctip2+ cortical layer neurons per view-

848 field in an/an mice versus +/+ littermates without reduction in the relative number of both layers.

849 Throughout these graphs $n=7$ animals/group and error bars indicate S.E.M., TT, $p<0.05,{ }^{* *} p$

$850<0.01,{ }^{* * *} \mathrm{p}<0.001,{ }^{* * * *} \mathrm{p}<0.0001$. For age as additional between subject factor see ANOVA

851 at table S1. 

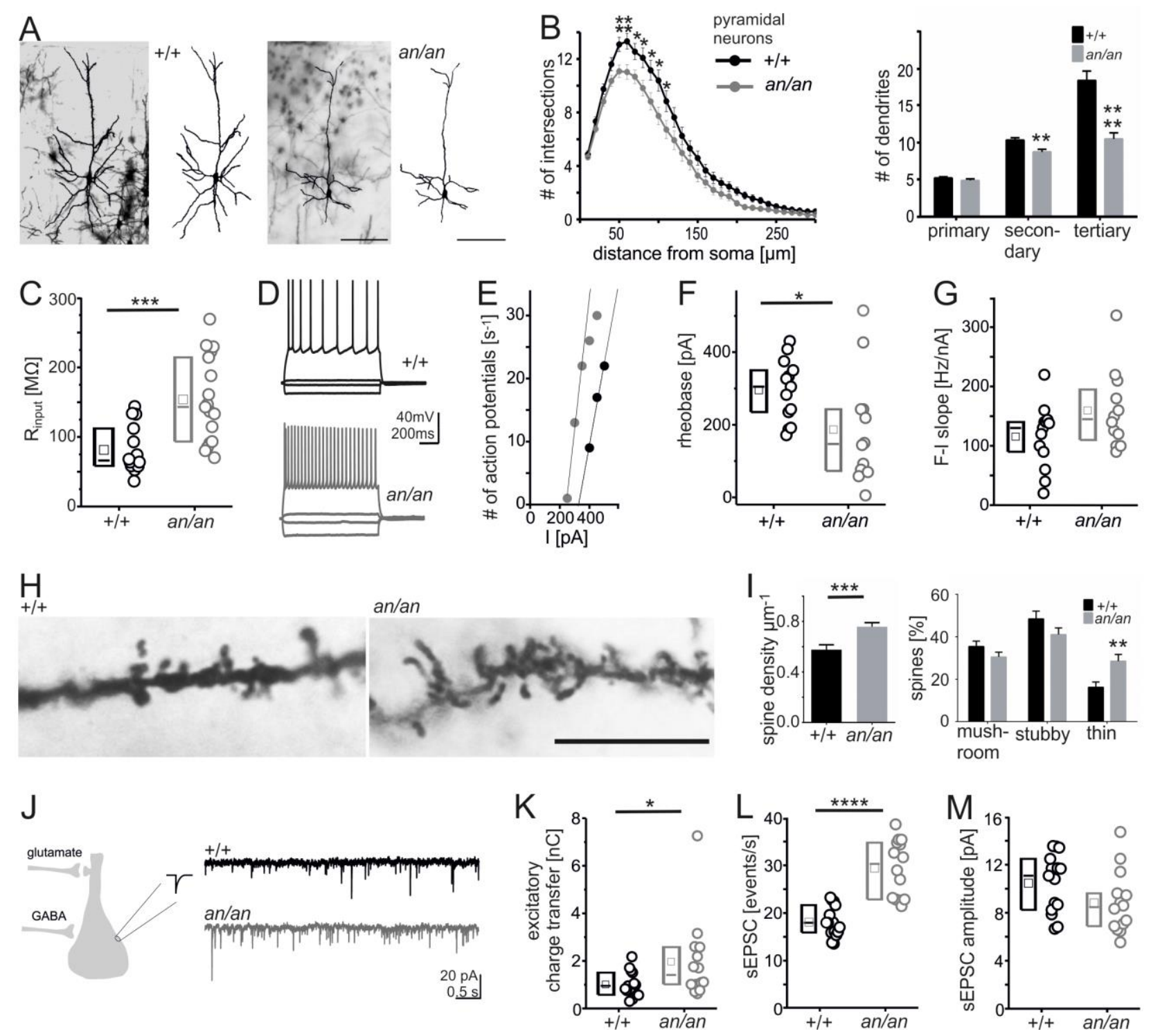

852

853 Fig 3. Distinctive morphological and physiological characteristics of layer $2 / 3$ pyramidal neurons from an/an mature neocortex. ( $\mathrm{A}$ and $\mathrm{B}$ ) Reduced dendritic complexity in

855 photomicrographs / reconstructed neurons (A, Golgi staining, scale bar $100 \mu \mathrm{m})$ as shown by less dendritic intersections $50-110 \mu \mathrm{m}$ from the soma and a reduction of the numbers of secondary and tertiary dendrites in an/an mice (B, Sholl analysis, $n=44+/+$ and 39 an/an neurons from $6+/+$ and 4 an/an animals). (C) Exemplary voltage responses to rectangular current injections (-200, \pm 50 and $400 \mathrm{pA}$ ) depicting firing behavior $(\mathrm{C})$ and the relation of elicited action potentials and the current injected (D). (E and F) Population data showing shifted neuronal offset $(E)$ and a trend towards an increased gain in an/an neurons (F). (G) Input resistance of an/an neurons was increased. $(\mathrm{H})$ Magnified image of secondary basal dendrites (Golgi staining, scale bar $10 \mu \mathrm{m}$ ). (I) Average spine density was increased (left) with a larger 
864 proportion of thin-shaped immature spines in an/an mice (right, $\mathrm{n}=410+/+$ and 373 an/an 865 spines counted in $34(+/+)$ and 30 (an/an) $20 \mu \mathrm{m}$ long dendritic segments from 5 866 animals/group). (J) Scheme and example traces of sEPSCs recordings in neurons voltage 867 clamped at $-60 \mathrm{mV}$. (K) Box plots showing an increased total excitatory charge transfer in an/an 868 mice due to increased sEPSCs frequency (L). (M) Average amplitudes were not altered. Serial 869 resistance $\left(R_{s_{+}+}=9.8 \pm 0.7 \mathrm{M} \Omega\right.$ vs. $R_{s a n / a n}=11.0 \pm 0.6 \mathrm{M} \Omega, p=0.1$; not shown $)$ was 870 comparable. Population data for E-G and K-M are from $15+/+$ and 14 an/an neurons from 4 871 animals / group; age: P30 - P80). Boxes in this and the following figures represent 25-75\% 872 plots, means and medians are depicted by an open square and a horizontal line, respectively. 

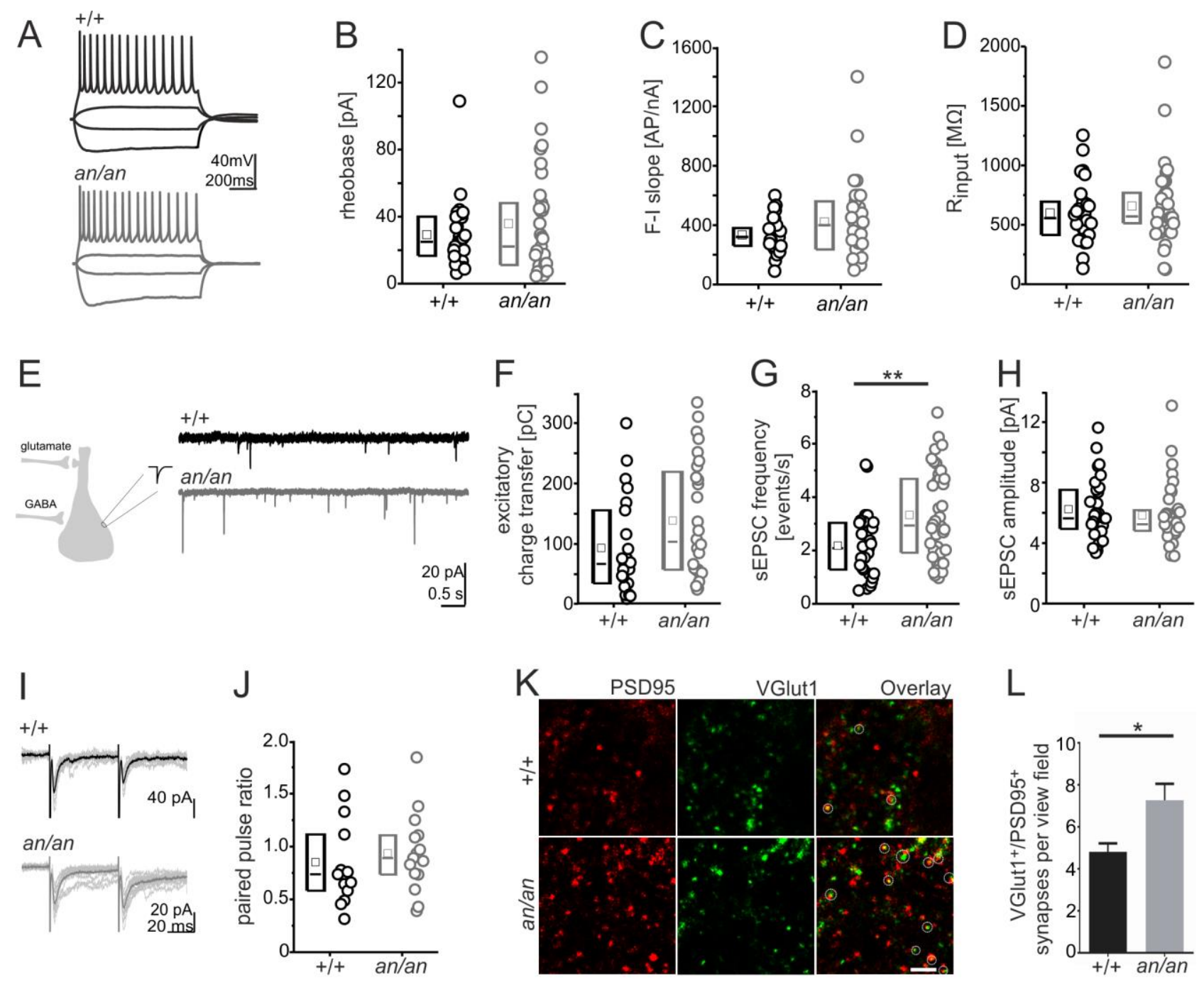

873

874 Fig 4. Increased excitatory synapse number and frequency of sEPSCs of layer 2/3 neocortical

875 pyramidal neurons at onset of synaptogenesis (P6/7). (A) Voltage changes of exemplary $+/+$

876 (top) and an/an (bottom) neurons to rectangular current injections of $-100, \pm 25$ and $100 \mathrm{pA}$. (B

877 and C) Population data on neuronal offset (B) and gain (C) revealed no differences. (D) Input

878 resistance did not vary between +/+ and an/an neurons. (E) Scheme and example traces for

879 SEPSC recordings in neurons voltage clamped at $-60 \mathrm{mV}$. ( $F$ and $G$ ) Box plot graphs displaying

880 values from $29+/+$ and 38 an/an neurons from 4 animals/group, showing a trend towards

881 increased total excitatory charge transfer in an/an mice $(F)$ and an increase in sEPSC

882 frequency in neurons from an/an mice (G). (H) Average amplitudes remained unchanged.

883 Serial resistance $\left(\mathrm{Rs}_{+/+}=9.1 \pm 0.5 \mathrm{M} \Omega\right.$ vs. $\mathrm{Rs}_{a n / a n}=8.8 \pm 0.4 \mathrm{M} \Omega, \mathrm{p}=0.57$; not shown $)$ was

884 similar. (I) Synaptic responses evoked by electrical stimulation overlay of 10 individual traces

885 recorded with $20 \mathrm{sec}$ intervals and a highlighted average trace. $(\mathrm{J})$ population data of paired 
886 pulse ratio $\left(\mathrm{PPR}_{+/+}=0.85 \pm 0.11\right.$ vs. $\left.\mathrm{PPR}_{a n / a n}=0.93 \pm 0.09, \mathrm{p}=0.6\right)$. (K) $100 \mu \mathrm{m}^{2}$ images of 887 the upper layer of the parietal cortex at upper layer areas from littermate animals stained for 888 VGlut1 (excitatory-presynaptic) and PSD95 (postsynaptic) markers. Overlay depicts 889 VGlut1/PSD95 positive synapses (dotted circles) (confocal images, scale bar $2 \mu \mathrm{m}$ ). (L) The 890 number of VGlut1/PSD95 positive synapses at layer 2/3 areas is increased in an/an mice (+/+ $891=4.8 \pm 0.4$ vs. an/an $=7.3 \pm 0.8 ; n=18$ images from $4+/+$ animals and 28 images from 5 an/an 892 animals). 

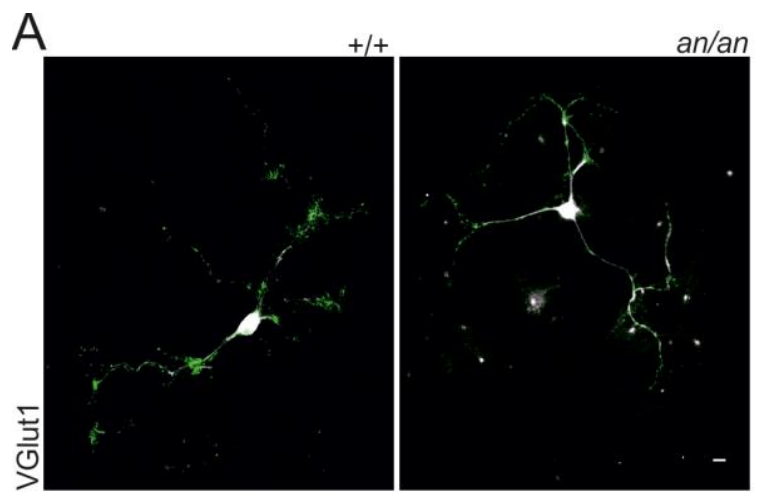

B
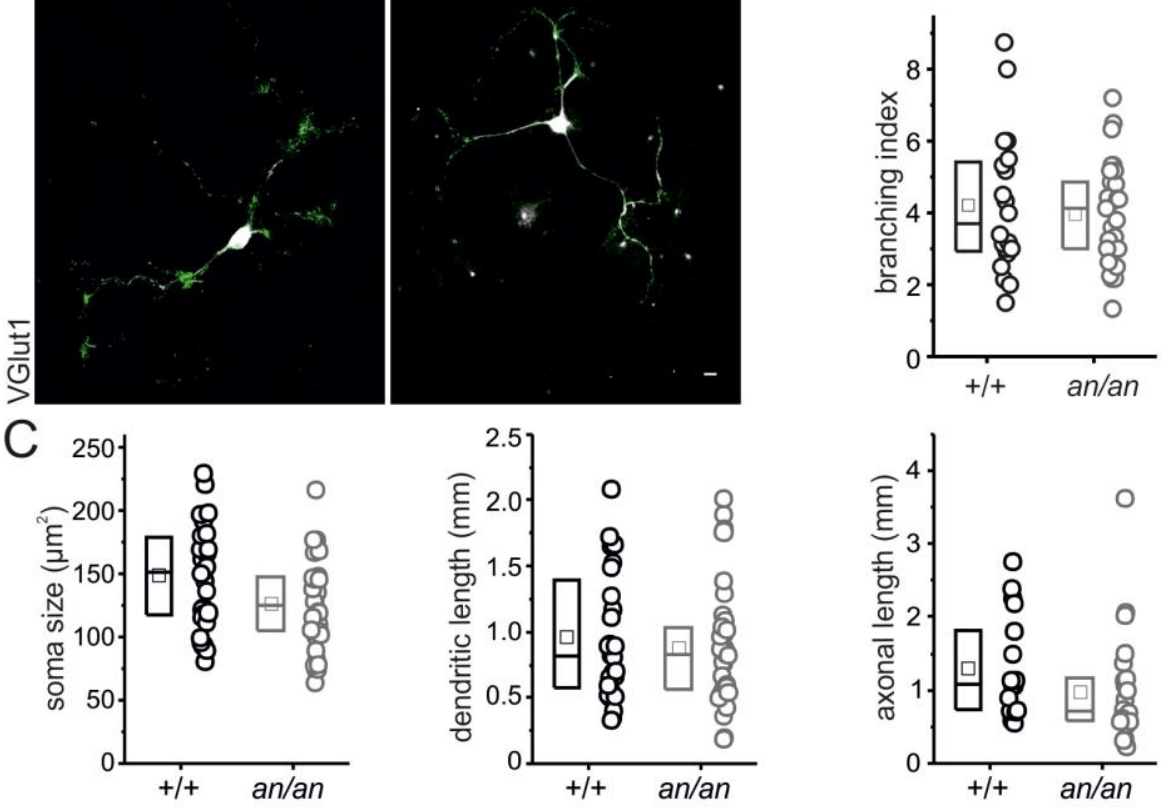

D

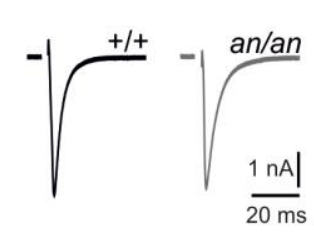

E
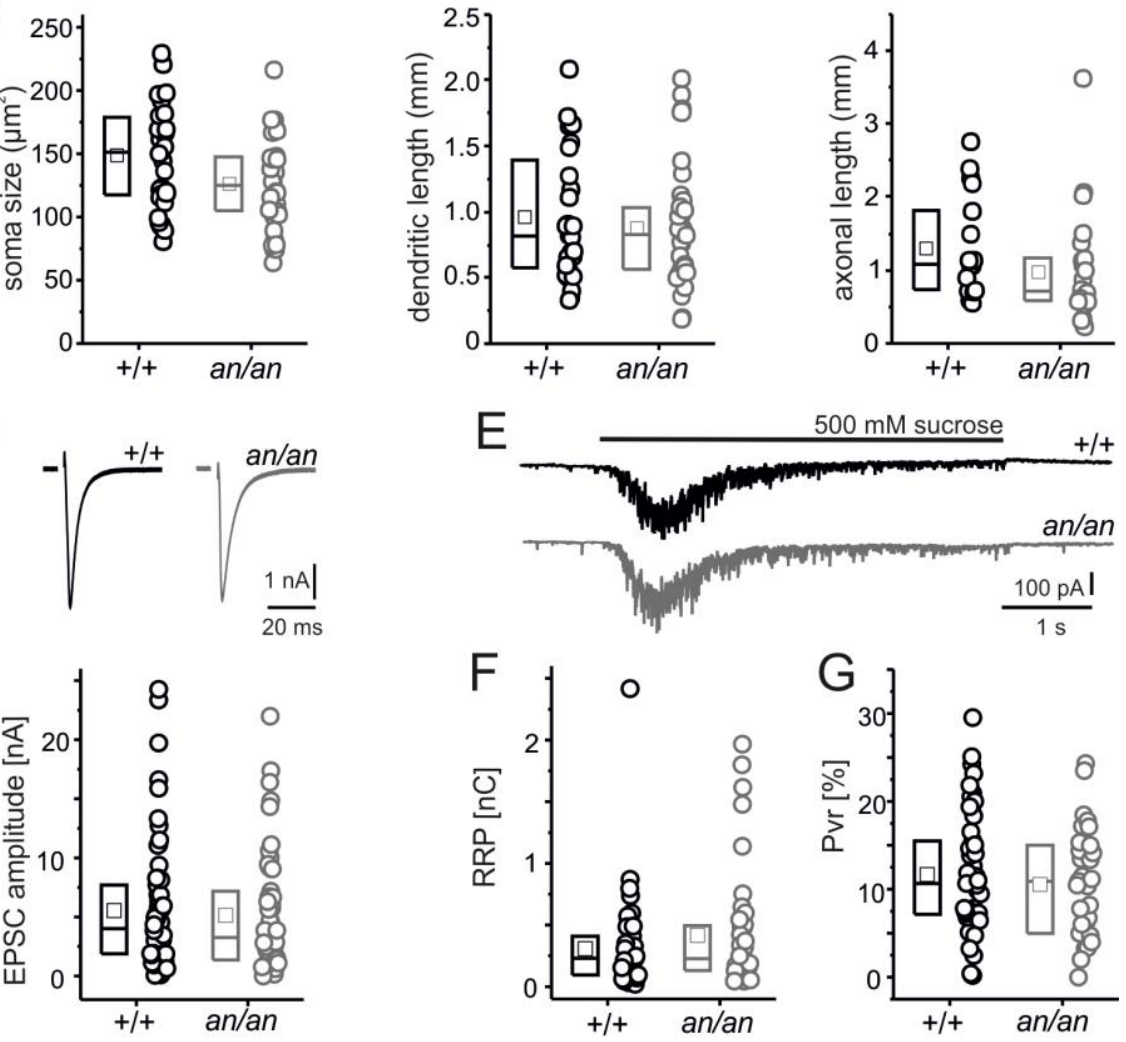

500 mM sucrose

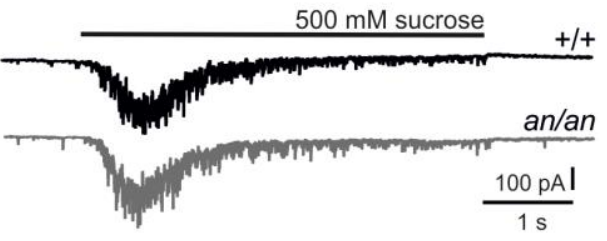

$\mathrm{H}$

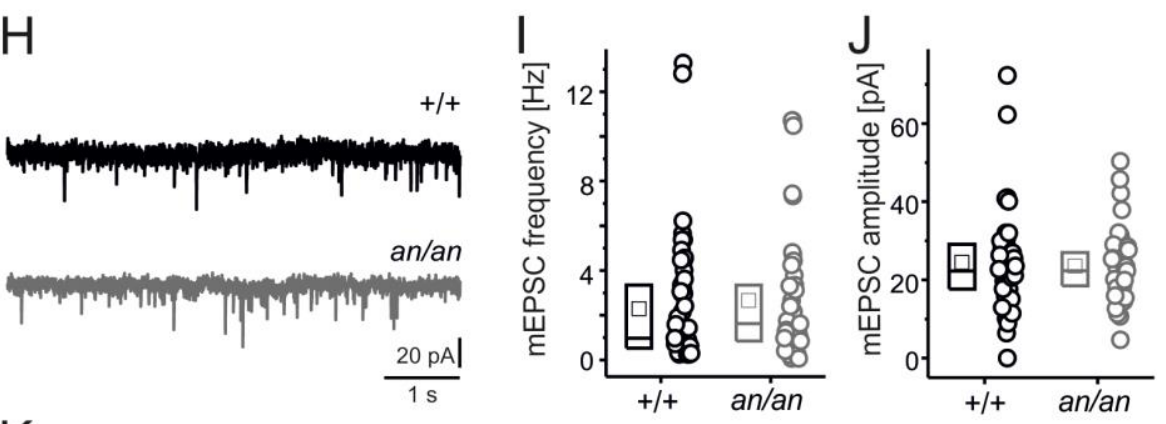

K
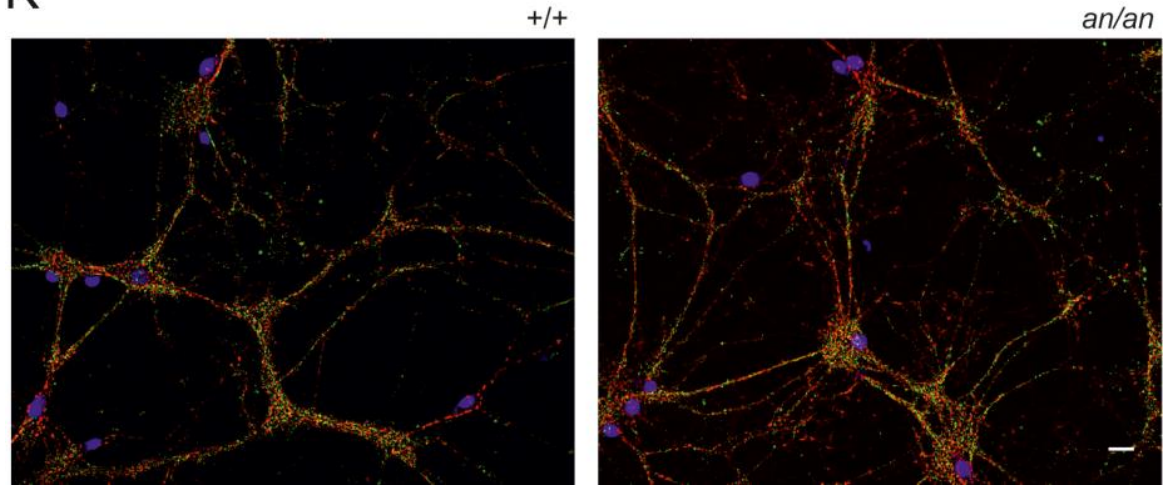
895 Fig 5. Neocortical pyramidal neurons derived from an/an and +/+ mice display a comparable 896 phenotype in vitro. (A) Photomicrographs of cultured neurons stained for neuronal cytoskeleton 897 by microtubule associated protein (Map2 - white, all panels) and VGlut1 (green), scale bar: 10 $898 \mu \mathrm{m}$. (B) Box plots of branching index estimated by the ratio of counts of dendritic tips / primary 899 dendrites confirm a lack of alteration in branching patterns. (C) Box plots illustrating soma size, 900 dendritic length and axonal length of autaptic cortical excitatory neurons. (D) Traces of 901 excitatory postsynaptic currents (top) after a $2 \mathrm{~ms}$ depolarization (EPSC) and population data 902 of EPSC amplitudes from $65+/+$ (black) and 54 an/an (grey) autaptic cortical neurons. (E) 903 Responses from +/+ (black) and an/an (grey) cortical neurons during $500 \mathrm{mM}$ sucrose 904 application for 5 s. (F) Box plot of readily releasable pool (RRP) and (G) average vesicular 905 release probability ( $P_{v r}=$ EPSC charge / RRP charge) in autaptic +/+ (51) and an/an (44) 906 cortical excitatory neurons. (H) Traces of mEPSC from +/+ (black) and an/an (grey) neurons. 907 (I and J) Box plots of mEPSC frequencies (I) and mEPSC amplitudes ( $\mathrm{J},+/+: 47$ neurons; 908 an/an: 43 neurons). Data was collected from 2 independent cultures. (K) Examples of 909 continental (high density) cultures stained for presynaptic markers VGlut (green), VGat (red) 910 and the nuclear marker DAPI (blue), scale bar: $25 \mu \mathrm{m}$. 

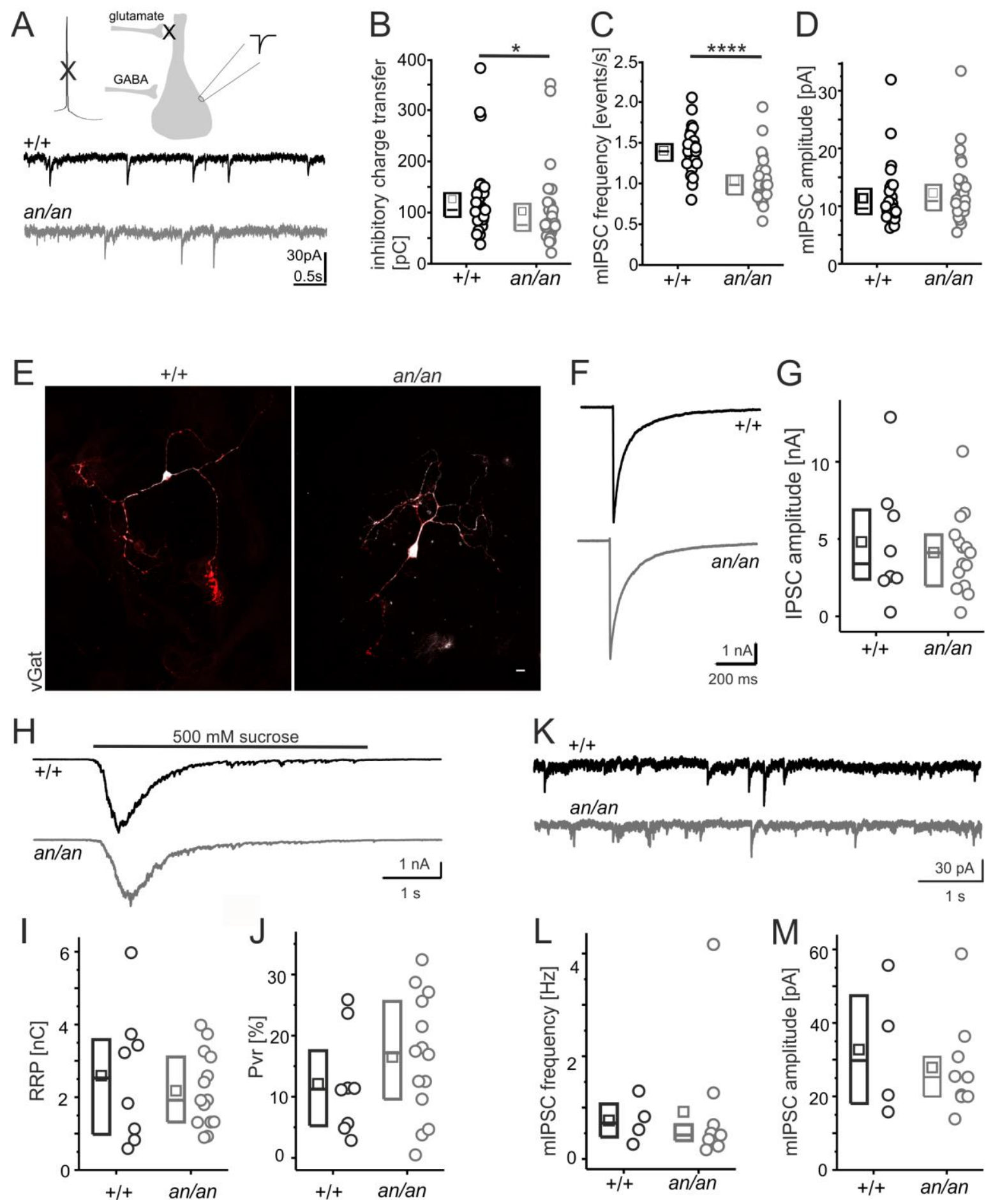

912 Fig 6. Decreased inhibition at the soma of layer $2 / 3$ neocortical ex-vivo pyramidal neurons in

$913 \mathrm{P} 6 / 7$ but not in cultured neurons from an/an mice. (A) Scheme and example of mIPSCs traces

914 recorded at $-60 \mathrm{mV}$ using equimolar $\mathrm{Cl}^{-}$and blocking excitatory postsynaptic currents with

915 CNQX and DAP-5 $(n=30+/+$ and 32 an/an neurons from 3 animals/group). (B and C) Box

916 plots showing a decreased total inhibitory charge transfer in an/an mice (B) due to reduced

917 mIPSCs frequency in an/an neurons (C). (D) Box plot graph depicting the mean mIPSC 
918 amplitudes shows no alteration between neurons from +/+ and an/an mice. Note that the slight 919 reduction in serial resistance of an/an cells $\left(R_{s+/+}=11.6 \pm 0.7 \mathrm{M} \Omega\right.$ vs. $R_{s a n / a n}=9.3 \pm 0.6 \mathrm{M} \Omega, p$ $920=0.009$; not shown) might attenuate the difference in frequencies between the groups. $(E)$ 921 Photomicrographs of autaptic inhibitory neurons stained for Map2 (white) and VGat (red), scale 922 bar: $10 \mu \mathrm{m}$. (F) Traces of inhibitory postsynaptic currents evoked by a 2 ms depolarization 923 (IPSC). (G) Population data of evoked IPSC amplitudes from +/+ (black) and an/an (grey) 924 autaptic cortical neurons. (H) Responses from +/+ (black) and an/an (grey) cortical neurons 925 during $5 \mathrm{~s}$ application of $500 \mathrm{mM}$ sucrose. (I) Box plot of readily releasable pool (RRP) and (J) 926 average vesicular release probability $\left(P_{v r}=\right.$ IPSC charge / RRP charge $)$ in autaptic $+/+$ and 927 an/an neurons. (K) Traces of mIPSCs from +/+ (black) and an/an (grey) neurons. ( $\mathrm{L}$ and $\mathrm{M})$ 928 Box plots of mIPSC frequencies (L) and mEPSC amplitudes (M). Data was collected from 2 929 independent cultures. 


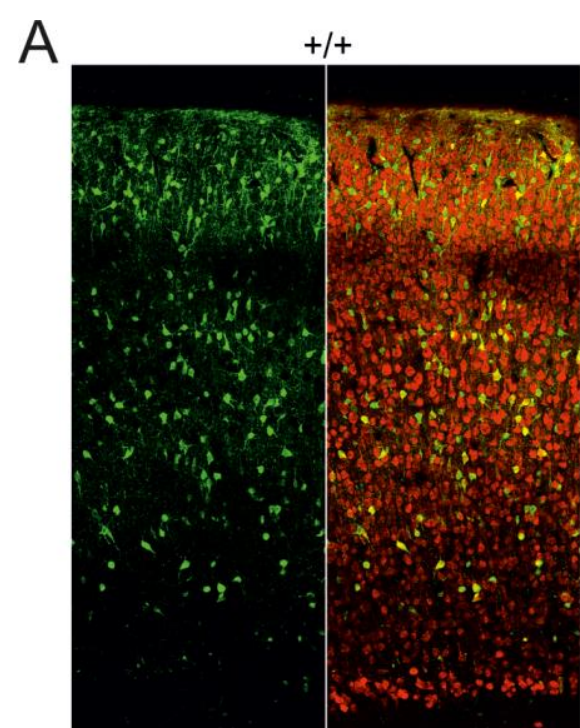

GABA

GABA / NeuN

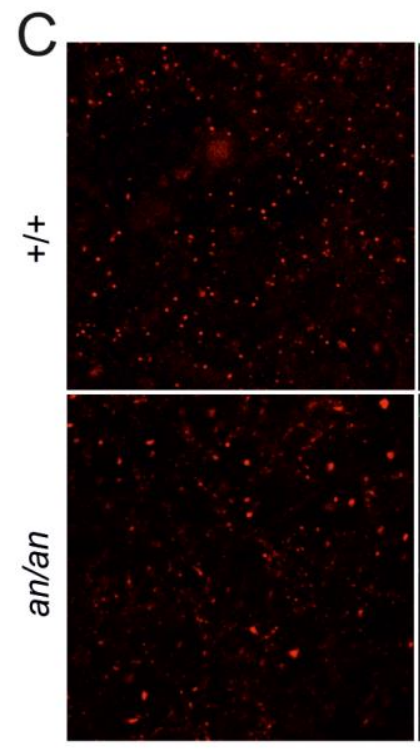

VGat

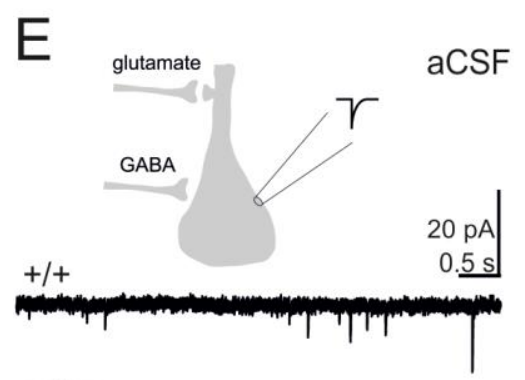

an/an

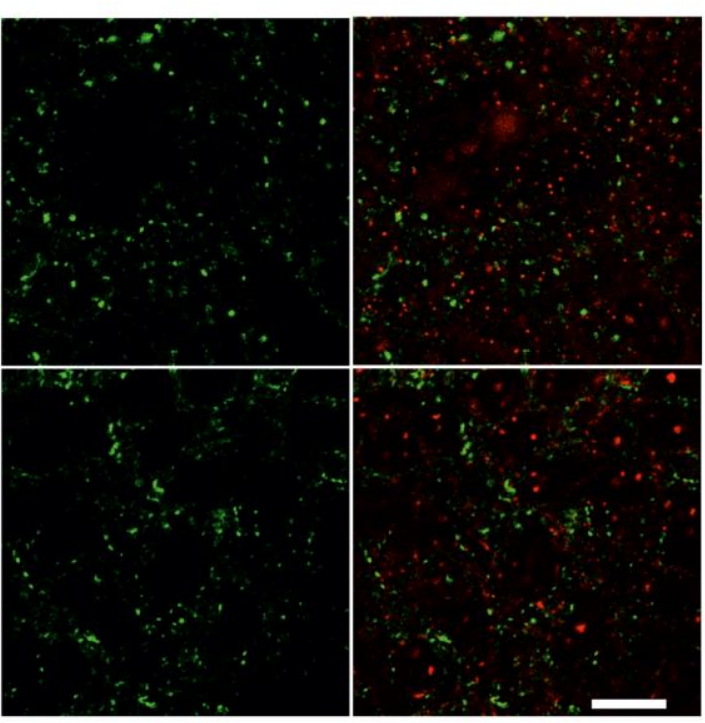

VGlut1

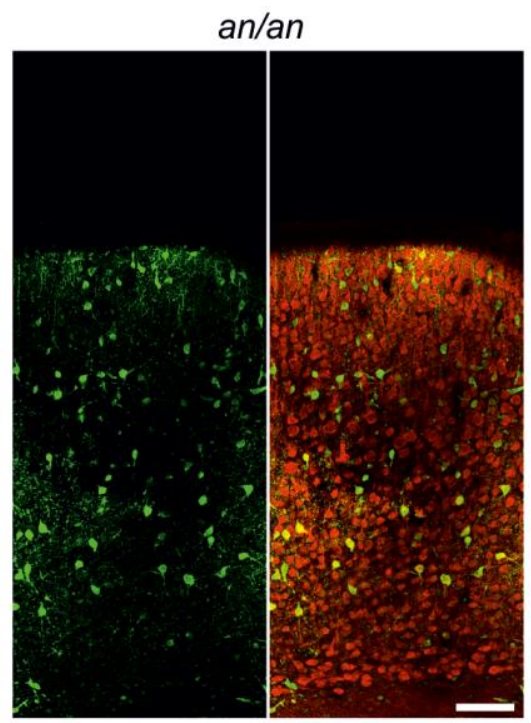

GABA

GABA / NeuN

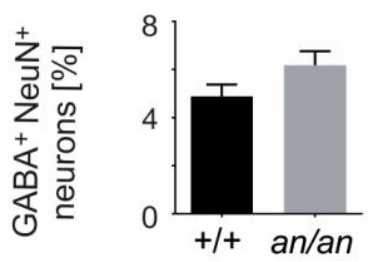

D
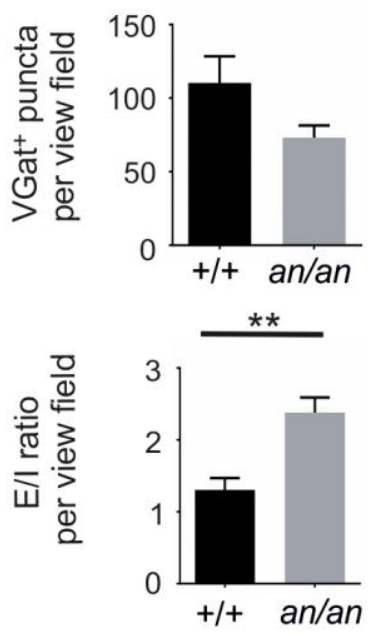

931 Fig 7. Loss of GABAergic input adjusts excitatory drive in neocortical layer 2/3 pyramidal

932 neurons of $+/+$ and an/an animals. (A) Coronal brain sections of P6-7 littermate animals stained

933 for the interneuron/astrocyte marker GABA (green) and the neuronal marker NeuN (red) 
934 (immunofluorescence images, scale bar $100 \mu \mathrm{m}$ ). (B) The total number GABA+ cells per view935 field is reduced in an/an mice but the proportion of these cells in relation to total $\mathrm{NeuN}^{+}$neurons 936 per view-field is comparable to +/+ mice. Note that there is no overlap of GABA and GFAP (Fig 937 S4), rendering an astrocytic contribution to $\mathrm{GABA}^{+}$cells unlikely. (C) Images of layer 2/3 areas $938\left(0.002 \mathrm{~mm}^{2}\right)$ of parietal cortices from littermate animals stained for VGlut1 (excitatory939 presynaptic) and VGat (inhibitory-presynaptic) markers (confocal images, scale bar $10 \mu \mathrm{m}$ ). 940 (D) The trend towards reduced number of inhibitory synapses contributes to an increased E/l 941 ratio at layer $2 / 3$ areas in an/an mice $n=15$ images from $6+/+$ animals and 20 images from 6 942 an/an animals). ( $E$ and $\mathrm{G}$ ) Comparative example of $\mathrm{mEPSCs}$ recorded at $-60 \mathrm{mV}$ before (E) 943 and after blocking spontaneous action potentials and $\mathrm{GABA}_{\mathrm{A}}$ receptors with tetrodotoxin and 944 bicuculline (+Bicu +TTX) (G) in +/+ (black) and an/an (grey) neurons. (F) Line series plots of 945 PSC frequencies before (aCSF) and after blocking spontaneous action potentials and 946 GABAergic transmission $(+B i c u+T T X)$. In neurons from $+/+$ mice the EPSC frequency 947 increased, whereas EPSC frequency remained comparable in an/an. Note that this differential 948 effect led to similar total excitatory charge transfer (not shown) and mEPSCs frequency. The 949 average amplitude was similar in $+/+$ and an/an pyramidal neurons $(n=30+/+$ and 26 an/an 950 neurons from 4 animals/group). The serial resistance was comparable $\left(R_{s+/+}=12.2 \pm 0.8 \mathrm{M} \Omega\right.$ $951 v s . \mathrm{R}_{\text {san } / a n}=11.5 \pm 0.8 \mathrm{M} \Omega, \mathrm{p}=0.8, \mathrm{MWU}$; not shown). 


\section{Supplementary figures and figure legends}

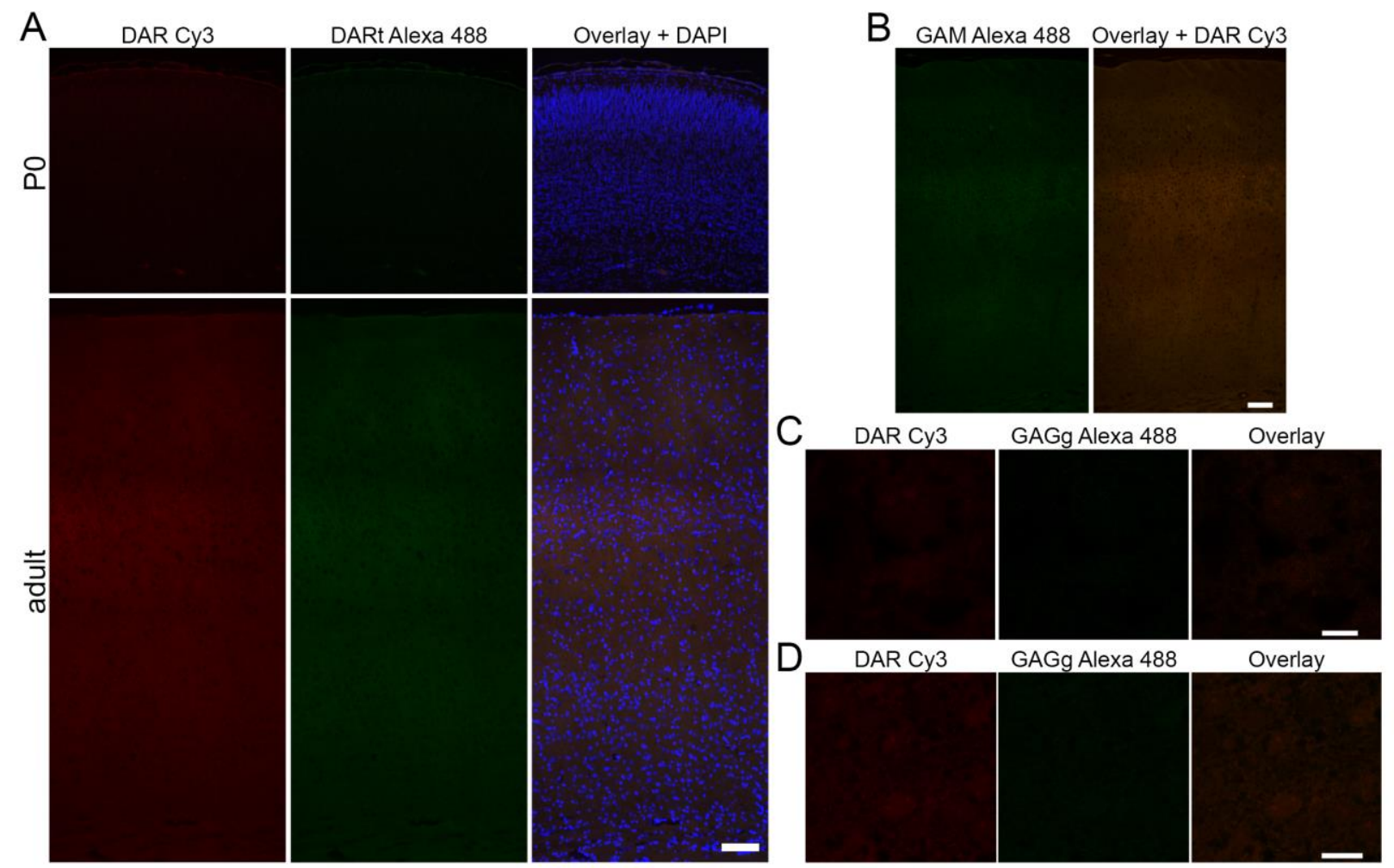

954 Fig S1. Negative control staining for Cux1, Ctip2, GABA, NeuN, PSD95, VGlut1 and VGat and

955 antibodies used in this study. (A) Secondary antibody staining for donkey anti-rabbit IgG Cy3

956 and donkey anti-Rat IgG Alexa Fluor 488 used to detect Cux1 and Ctip2 in (Fig 2A) respectively

957 (immunofluorescence images, scale bar $100 \mu \mathrm{m}$ ). (B) Secondary antibody staining for goat

958 anti-mouse IgG1 Alexa Fluor 488 and donkey anti-rabbit IgG Cy3 used to detect GABA and

959 NeuN in (Fig 7A) respectively (immunofluorescence images, scale bar $100 \mu \mathrm{m}$ ). (C) Secondary

960 antibody staining for donkey anti-rabbit IgG Cy3 and goat anti-guinea pig IgG Alexa Fluor 488

961 used to detect PSD95 and VGlut1 in (Fig 4K) respectively (confocal images, scale bar $2 \mu \mathrm{m}$ ).

962 Secondary antibody staining for donkey anti-rabbit IgG Cy3 and goat anti-guinea pig IgG Alexa

963 Fluor 488 used to detect VGat and VGlut1 in (Fig 7C) respectively (confocal images, scale bar $96410 \mu \mathrm{m})$. 

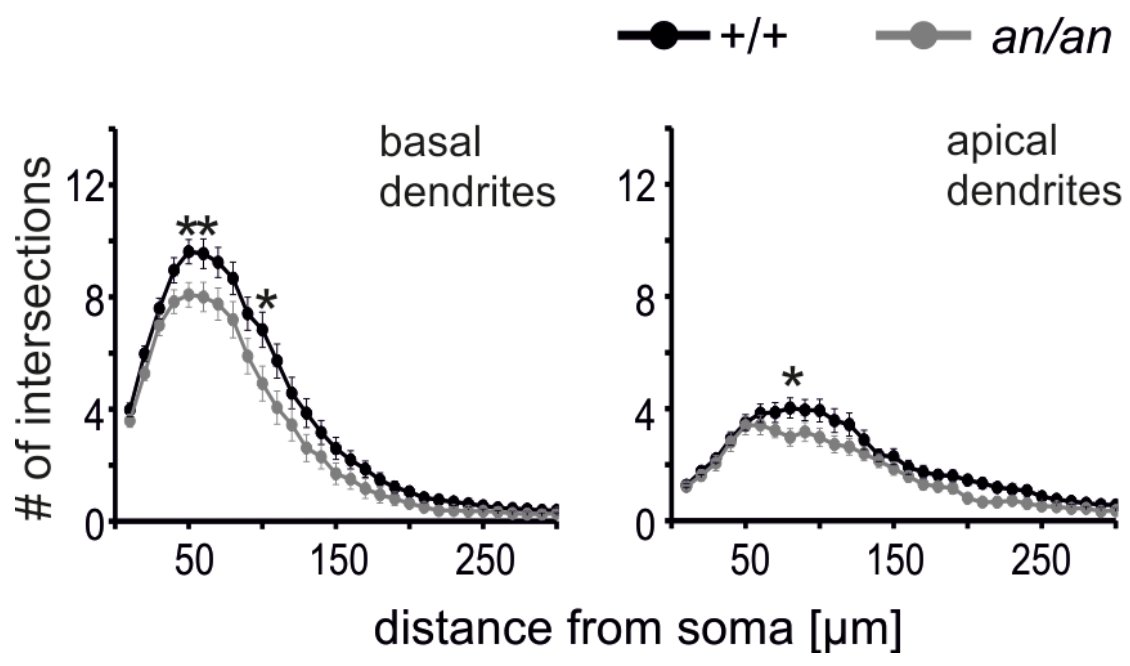

966 Fig S2. Reduced dendritic complexity of layer 2/3 pyramidal neurons from an/an mature neocortex. Sholl analysis shows that less dendritic intersections $50-110 \mu \mathrm{m}$ from the soma in 968 an/an mice (Fig 3B) is due to a reduction in apical and basal dendrites $(n=44+/+$ and 39 an/an 969 neurons from $6+/+$ and 4 an/an animals).

970

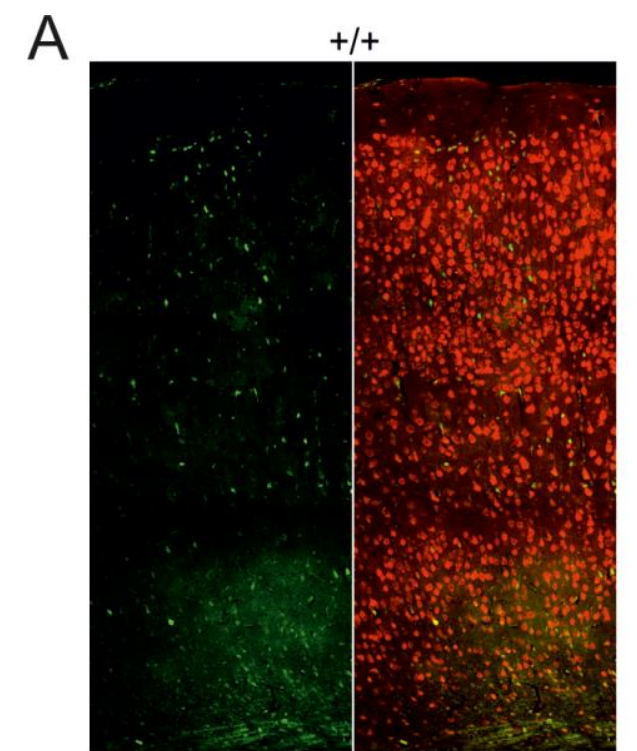

GABA

GABA / NeuN

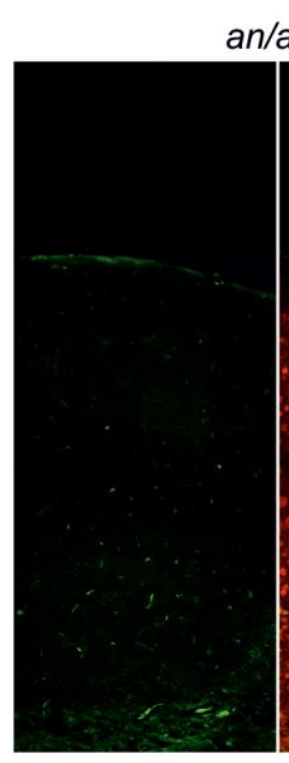

GABA an/an

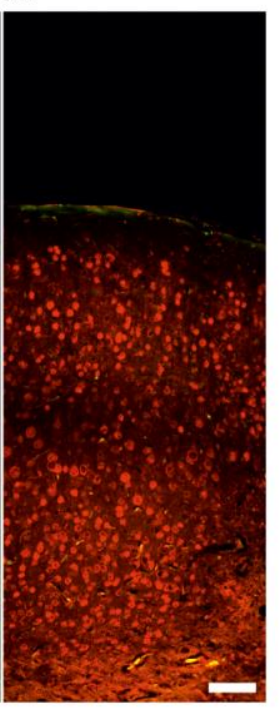

GABA / NeuN
B
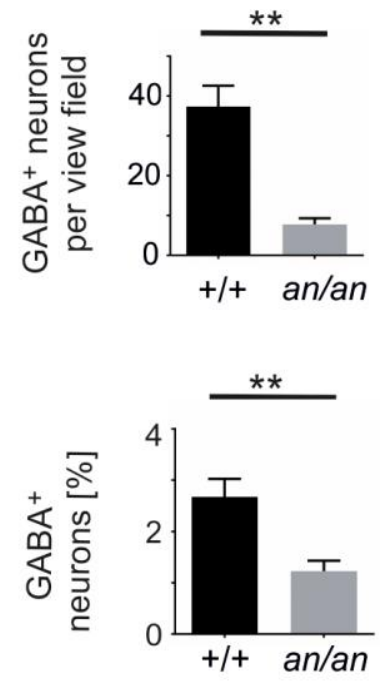

972 Fig S3. Loss of GABAergic input adjusts excitatory drive in neocortical layer 2/3 pyramidal

973 neurons of $+/+$ and an/an animals. (A) Coronal brain sections of adult littermate animals stained

974 for the interneuron marker GABA (GABA+ green) and the neuronal marker NeuN (red)

975 (immunofluorescence images, scale bar $100 \mu \mathrm{m}$ ). (B) The total number of interneurons positive

976 for GABA per view-field and the proportion of these cells in relation to total $\mathrm{NeuN}^{+}$neurons per

977 view-field is reduced in an/an mice. 


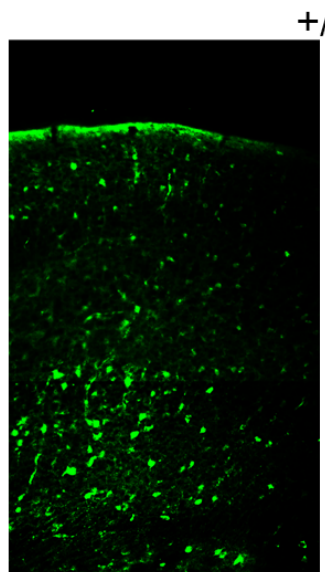

GABA

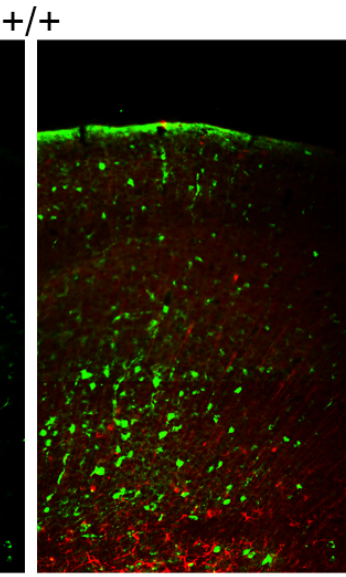

GABA / GFAP

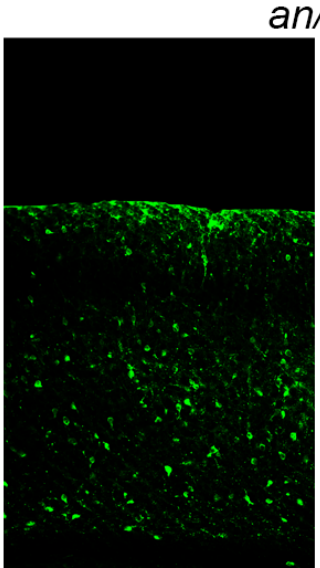

GABA an/an

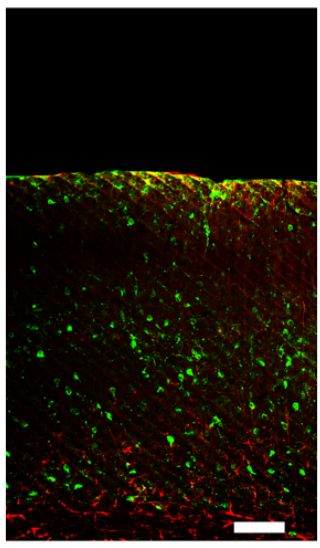

GABA / GFAP

Fig S4. No gross difference in the astrocyte distribution between $+/+$ and an/an animals.

980 Coronal brain sections of P6-7 littermate animals stained for the interneuron marker GABA

981 (GABA+ green) and the radial glial / astrocyte marker GFAP (GFAP+ red) (immunofluorescence 982 images, scale bar $100 \mu \mathrm{m})$. At this developmental age, only very few $\mathrm{GFAP}^{+}$astrocytes were 983 detected in the cortex and there was no GFAP/GABA overlap. 


\section{Supplementary tables}

985 Table S1. Data means and two-way ANOVAs for Fig 1 and Fig 2.

\begin{tabular}{|c|c|c|c|c|c|c|c|c|}
\hline \multirow{2}{*}{$\begin{array}{l}\text { Figure and } \\
\text { graph }\end{array}$} & \multirow{2}{*}{$\begin{array}{l}\text { Analyzed data / } \\
\text { marker }\end{array}$} & \multicolumn{2}{|c|}{ P0 (Mean \pm SEM) } & \multicolumn{2}{|c|}{ Adult $($ Mean \pm SEM) } & \multicolumn{3}{|c|}{ Two-way ANOVA } \\
\hline & & $+/+$ & an/an & $+/+$ & an/an & Interaction & Genotype & Age \\
\hline Fig 1B. left & Neocortical area & $3.9 \pm 0.1 \mathrm{~mm}^{2}$ & $1.8 \pm 0.2 \mathrm{~mm}^{2}$ & $29.4 \pm 1.0 \mathrm{~mm}^{2}$ & $14.7 \pm 1.0 \mathrm{~mm}^{2}$ & $\mathrm{P}<0.0001$ & $\mathrm{P}<0.0001$ & $\mathrm{P}<0.0001$ \\
\hline Fig 1B. right & Cortical thickness & $579.1 \pm 13.2 \mu \mathrm{m}$ & $388.3 \pm 17.8 \mu \mathrm{m}$ & $1381 \pm 48.2 \mu \mathrm{m}$ & $934.2 \pm 53.4 \mu \mathrm{m}$ & $\mathrm{P}=0.0027$ & $\mathrm{P}<0.0001$ & $\mathrm{P}<0.0001$ \\
\hline Fig 2B & $\mathrm{DAPI}^{+}$ & $2321 \pm 102.1$ cells & $1823 \pm 77.1$ cells & $1929 \pm 73.1$ cells & $959.6 \pm 29.5$ cells & $\mathrm{P}=0.0045$ & $\mathrm{P}<0.0001$ & $\mathrm{P}<0.0001$ \\
\hline \multirow{2}{*}{ Fig 2C. left } & $\mathrm{Cux}^{+}$ & $132.3 \pm 5.2 \mu \mathrm{m}$ & $87.1 \pm 6.7 \mu \mathrm{m}$ & $533.2 \pm 40.9 \mu \mathrm{m}$ & $298.4 \pm 15.6 \mu \mathrm{m}$ & $\mathrm{P}=0.0003$ & $\mathrm{P}<0.0001$ & $\mathrm{P}<0.0001$ \\
\hline & Ctip2 $^{+}$ & $333.3 \pm 12.3 \mu \mathrm{m}$ & $261.9 \pm 11.5 \mu \mathrm{m}$ & $621.4 \pm 29.5 \mu \mathrm{m}$ & $462.0 \pm 28.4 \mu \mathrm{m}$ & $\mathrm{P}=0.0585$ & $\mathrm{P}<0.0001$ & $\mathrm{P}<0.0001$ \\
\hline \multirow{2}{*}{ Fig 2C. right } & $\mathrm{Cux}^{+}$ & $25.7 \pm 1 \%$ & $21.5 \pm 1.2 \%$ & $36.4 \pm 1.2 \%$ & $30.9 \pm 1 \%$ & $\mathrm{P}=0.5614$ & $\mathrm{P}=0.0002$ & $\mathrm{P}<0.0001$ \\
\hline & Ctip2 $^{+}$ & $64.6 \pm 1.4 \%$ & $64.8 \pm 1.2 \%$ & $43 \pm 1.7 \%$ & $47.5 \pm 0.8 \%$ & $\mathrm{P}=0.1183$ & $\mathrm{P}=0.0855$ & $\mathrm{P}<0.0001$ \\
\hline \multirow{2}{*}{ Fig 2D. left } & $\mathrm{Cux}^{+}$ & $477.3 \pm 51.2$ neurons & $304.4 \pm 26.4$ neurons & $462.3 \pm 33.3$ neurons & $213.3 \pm 22$ neurons & $\mathrm{P}=0.2883$ & $\mathrm{P}<0.0001$ & $\mathrm{P}=0.1431$ \\
\hline & Ctip2 $^{+}$ & $675.0 \pm 27.8$ neurons & $516 \pm 33.9$ neurons & $263.3 \pm 28.1$ neurons & $151 \pm 10.1$ neurons & $\mathrm{P}=0.3873$ & $\mathrm{P}<0.0001$ & $\mathrm{P}<0.0001$ \\
\hline \multirow{2}{*}{ Fig 2D. right } & $\mathrm{Cux}^{+}$ & $20.3 \pm 1.5 \%$ & $16.6 \pm 1.1 \%$ & $24.2 \pm 2.1 \%$ & $22.2 \pm 2.1 \%$ & $\mathrm{P}=0.6456$ & $\mathrm{P}=0.1169$ & $\mathrm{P}=0.0130$ \\
\hline & Ctip2 $^{+}$ & $29.2 \pm 1.1 \%$ & $28.2 \pm 1.2 \%$ & $13.6 \pm 1.2 \%$ & $15.9 \pm 1.3 \%$ & $\mathrm{P}=0.1737$ & $\mathrm{P}=0.5814$ & $\mathrm{P}<0.0001$ \\
\hline
\end{tabular}

986 
Table S2. Age correlation analysis.

\begin{tabular}{|l|l|l|}
\hline Analyzed data & Prob>F & Pearson's r \\
\hline frequency & 0.83 & -0.04 \\
\hline amplitude & 0.73 & 0.07 \\
\hline decay time & 0.75 & -0.06 \\
\hline Cap & 0.06 & 0.36 \\
\hline Rinput & 0.46 & -0.15 \\
\hline rheobase & 0.82 & -0.05 \\
\hline slope & 0.34 & 0.21 \\
\hline membr & 0.24 & -0.28 \\
\hline GABA \# & 0.60 & -0.19 \\
\hline GABA \% & 0.40 & -0.30 \\
\hline neocortical area & 0.93 & 0.02 \\
\hline cortical thickness & 0.88 & -0.04 \\
\hline Cux1 \# & 0.53 & -0.18 \\
\hline Ctip2 \# & 0.54 & 0.18 \\
\hline DAPI \# & 0.75 & -0.09 \\
\hline Cux1 \% & 0.70 & -0.11 \\
\hline Ctip2 \% & 0.16 & 0.39 \\
\hline Cux1 thickness & 0.87 & -0.05 \\
\hline Ctip2 thickness & 0.52 & 0.19 \\
\hline DAPI thickness & 0.93 & 0.03 \\
\hline Cux1 thickness \% & 0.50 & -0.19 \\
\hline Ctip2 thickness \% & 0.36 & 0.27 \\
\hline primary dendrites & 0.60 & 0.20 \\
\hline secondary dendrites & 0.37 & -0.34 \\
\hline tertiary dendrites & 0.59 & 0.21 \\
\hline spine density & 0.14 \\
\hline Mushroom spines \% & 0.07 \\
\hline Stubby spines \% & 0.33 \\
\hline Thin spines \% & 0.36 \\
\hline
\end{tabular}

